\title{
Latent Modulation: A Basis for Non-Disruptive Promotion of Two Incompatible Behaviors by a Single Network State
}

\author{
Andrew M. Dacks and Klaudiusz R. Weiss \\ Department of Neuroscience, Mount Sinai School of Medicine, New York, New York 10029
}

Behavioral states often preferentially enhance specific classes of behavior and suppress incompatible behaviors. In the nervous system, this may involve upregulation of the efficacy of neural modules that mediate responses to one stimulus and suppression of modules that generate antagonistic or incompatible responses to another stimulus. In Aplysia, prestimulation of egestive inputs [esophageal nerve $(\mathrm{EN})$ ] facilitates subsequent EN-elicited egestive responses and weakens ingestive responses to ingestive inputs [Cerebral-Buccal Interneuron (CBI-2)]. However, a single state can also promote incompatible behaviors in response to different stimuli. This is the case in Aplysia, where prestimulation of CBI-2 inputs not only enhances subsequent CBI-2-elicited ingestive responses, but also strengthens EN-elicited egestive responses. We used the modularly organized feeding network of Aplysia to characterize the organizational principles that allow a single network state to promote two opposing behaviors, ingestion and egestion, without the two interfering with each other. We found that the CBI-2 prestimulation-induced state upregulates the excitability of neuron B65 which, as a member of the egestive module, increases the strength of egestive responses. Furthermore, we found that this upregulation is likely mediated by the actions of the neuropeptides FCAP (Feeding Circuit Activating Peptide) and CP2 (Cerebral Peptide 2). This increased excitability is mediated by a form of modulation that we refer to as "latent modulation" because it is established during stimulation of CBI-2, which does not activate B65. However, when $\mathrm{B} 65$ is recruited into EN-elicited egestive responses, the effects of the latent modulation are expressed as a higher B65 firing rate and a resultant strengthening of the egestive response.

\section{Introduction}

The concepts of network states and of modular organization of networks are often used to explain how nervous systems generate different behaviors. Modules are defined as groups of neurons responsible for the implementation of individual components of a behavior (Briggman and Kristan, 2008). Emphasis is therefore placed on the consistency with which an individual stimulus activates a specific combination of modules and thereby elicits the same type of behavior, although not necessarily with equal strength. In contrast, the very existence of distinct network states is inferred by the generation of different behaviors to a constant stimulus at different times. How then can multiple behaviors be controlled by states in a modularly organized nervous system without specific behaviors interfering with each other? Network states are often defined by the behavior that they promote (e.g., hunger promotes eating). Within this framework there is no conflict between the concepts of modules and states as, without changing the composition of modules, states can simply enhance

Received Nov. 20, 2012; revised Dec. 22, 2012; accepted Jan. 5, 2013.

Author contributions: A.M.D. and K.R.W. designed research; A.M.D. performed research; A.M.D. analyzed data; A.M.D. and K.R.W. wrote the paper.

This research was funded by National Institutes of Health Grants NS066587 and NS070583 to K.R.W. We thank Dr. E. Cropper, Dr. J. Jing, Dr. B. Ludwar, M. Perkins, and M. Siniscalchi for technical assistance, helpful discussions, and careful critique of this manuscript. We also thank Dr. J. Sweedler for generously providing the FCAP.

The authors declare no competing financial interests.

Correspondence should be addressed to Dr. Andrew Dacks, Department of Neuroscience, Box 1065, Mount Sinai School of Medicine, 1 Gustav Levy Place, New York, NY 10029. E-mail: adacks@gmail.com.

DOI:10.1523/JNEUROSCI.5371-12.2013

Copyright $\odot 2013$ the authors $\quad 0270-6474 / 13 / 333786-13 \$ 15.00 / 0$ their level of activity or efficacy. Additionally, behavioral states often suppress responses antagonistic to the responses being enhanced (MacFadyen et al., 1973; Rogers and Monsell, 1995; Meiran et al., 2000; Keene et al., 2010; Kiesel et al., 2010), and consistent with this, states often enhance the efficacy of specific behavior promoting modules while suppressing modules promoting antagonistic responses (Proekt et al., 2004, 2007; Wu et al., 2010). However, it is difficult to reconcile the two concepts when network states promote incompatible behaviors as observed in vertebrates and invertebrates (Rechtschaffen et al., 2002; Jing et al., 2008; McDonald and Keene, 2010). How, then, can a single network state promote the efficacy of two incompatible modules without disrupting the responses in whose generation they are involved? We used the feeding central pattern generator (CPG) of Aplysia, to show how this can be achieved.

In the feeding CPG of Aplysia repeated stimulation of specific inputs establishes a history-dependent network state manifested as an enhancement of subsequent responses to the previously stimulated input. When motor programs are triggered by the command neuron CBI-2, subsequent responses to CBI-2 stimulation become increasingly ingestive (Proekt et al., 2004; Friedman and Weiss, 2010; Dacks et al., 2012). However, subsequent responses to esophageal nerve (EN) stimulation, which signals inedible food stimuli, become increasingly egestive (Proekt et al., 2008). Ingestion and egestion involve opposite phasing of motor activity; thus, CBI-2 priming establishes a network state that simultaneously promotes antagonistic responses. Our data indicate that CBI-2 increases the excitability of a member neuron (B65) of the egestion-promoting module via peptidergic mecha- 
nisms and the resultant increase in B65 activity enhances subsequent egestive EN responses. B65 is active during EN responses, but not CBI-2 responses, and thus the alteration of B65s intrinsic properties is not manifested during the establishment of the CBI-2 primed network state and therefore does not disrupt the production of ingestive CBI-2 responses. We refer to this phenomenon as "latent modulation," which we believe may have important ramifications for understanding the behavioral consequences of network states.

\section{Materials and Methods}

Electrophysiological experiments and analyses. Adult sea slugs (Aplysia californica) were obtained from Marinus and maintained at $14-15^{\circ} \mathrm{C}$. Animals were anesthetized with isotonic $\mathrm{MgCl}_{2}$ and all experiments were performed at $14-15^{\circ} \mathrm{C}$. Either artificial sea water (in mM: $460 \mathrm{NaCl}, 10$ $\mathrm{KCl}, 55 \mathrm{MgCl}_{2}, 11 \mathrm{CaCl}_{2}$, and 10 HEPES buffer, $\mathrm{pH} 7.6$ ) or a $2 \mathrm{Mg}^{2+} / 1.25$ $\mathrm{Ca}^{2+}$ high divalent solution (HiDi; in mM: $368 \mathrm{NaCl}, 10 \mathrm{KCl}, 101 \mathrm{MgCl}_{2}$, $13.8 \mathrm{CaCl}_{2}$, and 10 HEPES, pH 7.6; Friedman and Weiss, 2010) was superfused onto the preparation at $0.3 \mathrm{ml} / \mathrm{min}$. Feeding Circuit Activating Peptide (FCAP; provided by Dr. J. Sweedler, University of Illinois, Urbana, IL; Sweedler et al., 2002) and Cerebral Peptide 2 (CP2; SynPep; Phares et al., 1996; Vilim et al., 2001) were applied at $1 \mu \mathrm{M}$ concentrations in HiDi and were prepared daily from frozen aliquots. Intracellular recordings were performed with borosilicate electrodes filled with $0.6 \mathrm{M}$ $\mathrm{K}_{2} \mathrm{SO}_{4}$ and $60 \mathrm{~mm} \mathrm{KCl}$ electrolyte solution. Electrodes were pulled with a Sutter Instrument Co. Flaming/Brown micropipette puller and beveled with a stream of aluminum oxide in water to a final resistance of 7-9 M $\Omega$ for motor neurons and 10-12 $\mathrm{M} \Omega$ for interneurons. Electrodes were held in Molecular Devices HS-2A headstages connected to AxoClamp 2B (Molecular Devices) amplifiers. In experiments in which 5 intracellular electrodes were needed, a Getting Instruments Model 5A microelectrode amplifier was used. Extracellular nerve recordings were performed by aspirating buccal nerve 2, I2 nerve, and the radular nerve into polyethylene tubing. Intracellular and extracellular signals were amplified by a CyberAmp 380 (Molecular Devices) and sent to a 1320A Digidata (Molecular Devices) for data acquisition. AxoScope v 10 (Molecular Devices) was used to visualize and record experiments. Data were analyzed in Spike 2 (Cambridge Electronic Design) and organized in Excel (Microsoft Corp.) for statistical analysis in GraphPad Prism v5.01. Error bars indicate SEM and $p<0.05$ was selected for significance tests. When ANOVA tests indicated significant effects, individual comparisons were calculated with a Bonferroni correction. Mean firing rate was calculated as the number of spikes within the duration of either protraction or retraction. Instantaneous firing rate was calculated as the number of spikes per second for each $500 \mathrm{~ms}$ bin from $10 \mathrm{~s}$ before to $10 \mathrm{~s}$ after the switch to retraction. Peak instantaneous firing rate was calculated as the maximal firing rate reached averaged across preparations. To avoid pseudo-replication in bilateral B65 experiments, mean protraction firing rate was averaged across both $\mathrm{B} 65 \mathrm{~s}$ for each animal.

Characterization of motor programs. The ingestive versus egestive nature of feeding responses depends on the coordination of movements of two sets of muscles groups: (1) those muscles that open and close the radula and (2) those that protract and retract the radula. Because feeding response always begins with protraction followed by retraction, the functional nature of feeding responses depends on the activation of the opener/closer motor neurons in relation to protraction and retraction. If the radula is open during protraction and then closed during retraction, the radula extends out, clamps down on a food item and draws it into the mouth (Kupfermann, 1974; Morton and Chiel, 1993a,b). This behavior is referred to as an "ingestive" response (Fig. 1A). If the radula is closed during protraction and then opens during retraction, the radula extends out, releases the food item and draws back into the mouth. This is referred to as an "egestive" response (Fig. 1B).

At the level of the nervous system, we use the firing of the radula closure neuron $\mathrm{B} 8$ in relation to the phasing of protraction and retraction (Morton and Chiel, 1993a,b; Jing and Weiss, 2001, 2002; Jing et al., 2004; Proekt et al., 2004, 2007; Friedman and Weiss, 2010) to determine the nature of motor programs. Protraction duration was defined as the pe- riod of activity of protraction motor neurons recorded extracellularly from the I2 nerve (Hurwitz et al., 1996; Nargeot et al., 1999a,b; Morgan et al., 2000; Jing and Weiss, 2001, 2002), while retraction duration was defined as the period of high-frequency activity of large motor units recorded extracellularly from buccal nerve 2 following protraction (Morton and Chiel, 1993a,b; Nargeot et al., 1999b). If B8 activity is high during protraction and low during retraction, motor programs are considered egestive (Fig. 1C1) in that the radula closes on a food item as the radula extends out of the mouth, thus pulling the food item with it (Fig. $1 A)$. If $\mathrm{B} 8$ activity is low across protraction and retraction, motor programs are intermediate (Fig. 1C2). If B8 activity is low in protraction and high in retraction, motor programs are ingestive (Fig. 1C3) in that the radula closes on the food item as the radula retracts, thus drawing the food item into the mouth (Fig. 1B).

We also use the phasing of B8 activity to monitor the effects of repeated stimulation of different inputs to the CPG. Stimulation of different inputs to the CPG elicits distinct motor programs and repeated activation of these inputs modifies subsequent motor programs. Figure $1 D$ depicts the two-dimensional space of B8 activity in protraction and retraction phases that we use to characterize the programs as ingestive versus egestive. This figure also depicts the effects of recent history of input activation on the CPG output as plotted in this two-dimensional space. When preparations are in the "default" baseline state, stimulating the command neuron CBI-2 or the EN programs elicits intermediate motor programs. Repeatedly triggering EN programs ("egestive priming") promotes the implementation of egestive responses to subsequent EN or CBI-2 stimulation (Proekt et al., 2004, 2007; Wu et al., 2010). However, repeatedly triggering CBI-2 programs ("CBI-2 priming") promotes the implementation of ingestive responses to subsequent CBI-2 stimulation (Proekt et al., 2004; Friedman and Weiss, 2010) and egestive responses to subsequent EN stimulation (Proekt et al., 2008).

Selection and identification of neurons. The choice of neurons whose functions we seek to characterize is based on our understanding of the neural connections and patterns of activity of the CPG elements that contribute to the ingestiveness or egestiveness of motor program that are elicited by stimulation of EN and/or CBI-2 inputs to the CPG. This understanding is illustrated in a simplified manner in Figure 1, $E$ and $F$, which shows the patterns of activity and synaptic connections of partially overlapping sets of interneurons that are activated by CBI-2 and EN (respectively) and provide inputs to radula closure motoneuron B8. The output of B8 in response to CBI-2 and EN stimulation is not shown as this $\mathrm{B} 8$ activity depends on the network state (see Fig. 1D). CBI-2 drives several interneurons that provide a balance of excitation and inhibition to $\mathrm{B} 8$ during both protraction and retraction (Fig. $1 E$ ). CBI-2 activates the protraction interneuron $\mathrm{B} 40$ which inhibits $\mathrm{B} 8$ during protraction and excites B8 during retraction, and thus is a member of the ingestionpromoting module (Jing and Weiss, 2002; Jing et al., 2004). CBI-2 also weakly activates the protraction interneuron B20 (Teyke et al., 1993) which provides excitatory drive to $\mathrm{B} 8$ during protraction and drives B4/5, which inhibits B8 during retraction (Gardner and Kandel, 1977; Kabotyanski et al., 1998; Jing and Weiss, 2001). Finally, CBI-2 directly inhibits B65 (Jing and Weiss, 2005; Proekt et al., 2007). Stimulating the EN provides excitatory input to B4/5, B65, and B20 (Fig. $1 F$ ). B20 and B65 provide excitatory drive to $\mathrm{B} 8$ during protraction and depolarize $\mathrm{B} 4 / 5$, and are members of the egestion-promoting module. Furthermore, B65 provides direct excitatory synaptic input to B20 (Jing and Weiss, 2001). Thus, competing modules are activated by different stimuli that promote the two incompatible behaviors (Jing and Weiss, 2001, 2002, 2005; Jing et al., 2004).

All neurons were identified based on previously published physiological criteria. B8 is a large motor neuron located on the ventrolateral surface of the buccal ganglion and its spiking activity is monitored by extracellular recording from the radula nerve (Morton and Chiel, 1993b). B4/5 are large cells sitting on the ventromedial rostral surface of the buccal ganglion and produce one-for-one IPSPs in B8 (Gardner, 1977). B65 is located on the caudal surface of the buccal ganglion at the intersection of the axonal bundles from the esophageal nerve and buccal nerve 1 and elicits large depressing EPSPs in B4/5 (Kabotyanski et al., 1998). The command neuron CBI-2 is located in the M-cluster of the 
A

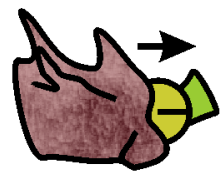

Radula protracts closed

B

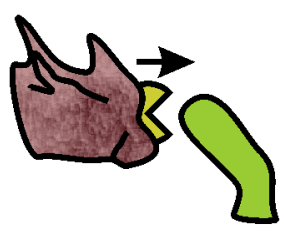

Egestion
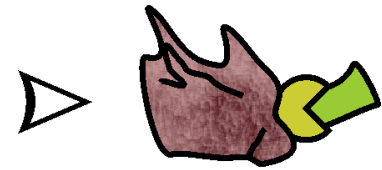

Radula opens

Ingestion

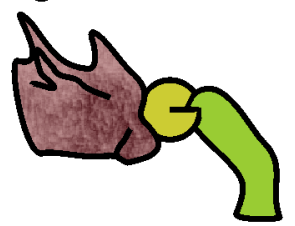

Radula closes
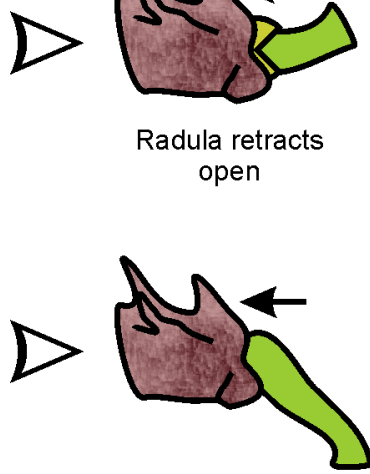

Radula retracts closed
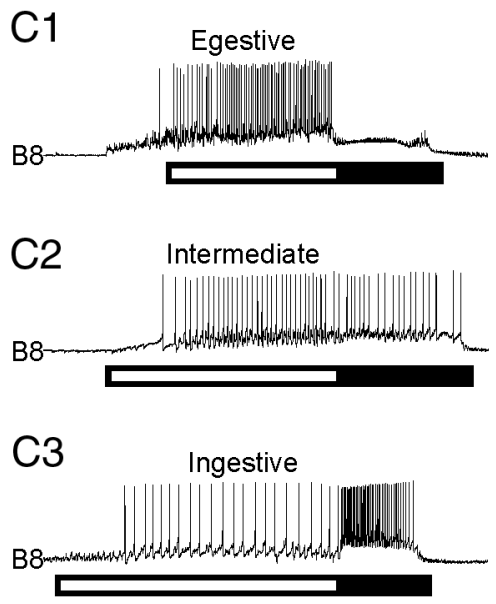

E

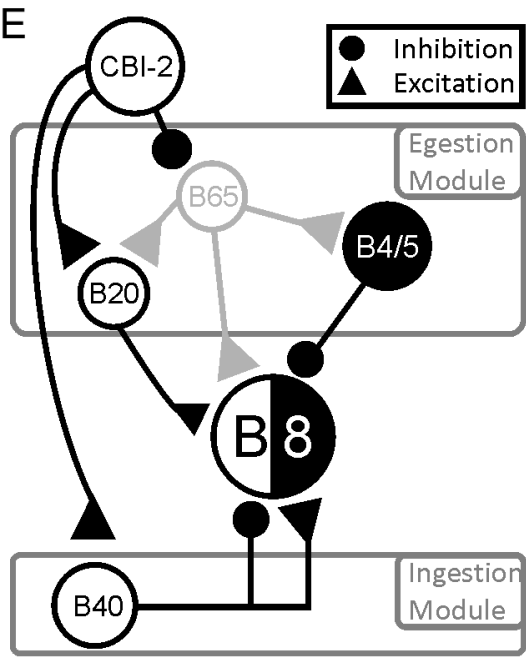

Protraction Retraction
D

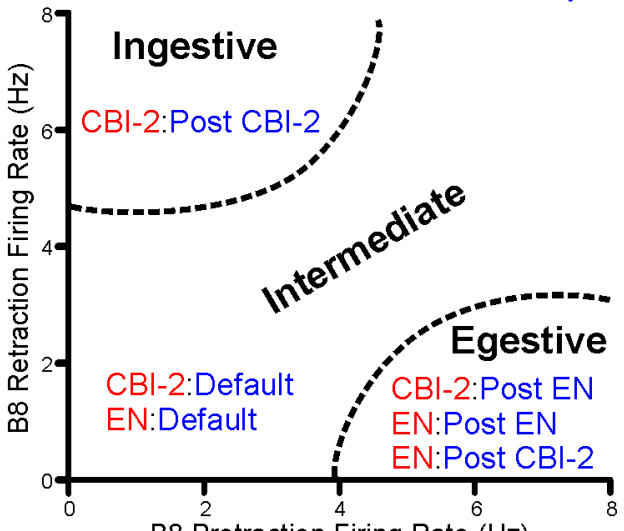

B8 Protraction Firing Rate $(\mathrm{Hz})$

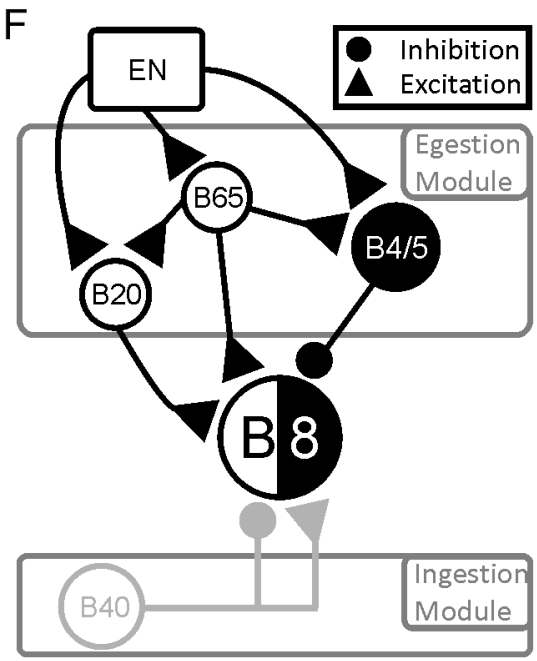

Protraction Retraction

Figure 1. Classification of feeding responses and schematic representation of the buccal network. $A$, Illustration of the radula movements that occur during egestion. The radula is protracted while closed on the seaweed. Once fully extended the radula opens and retracts. $\boldsymbol{B}$, Illustration of the radula movements that occur during ingestion. The radula is protracted open toward the seaweed. The radula closes on the seaweed and remains closed as the radula is retracted into the mouth. $\boldsymbol{C}$, Example traces of the activity of the radula closure motor neuron B8 across protraction (white bar) and retraction (black bar) in egestive ( $\mathbf{C}$, top trace), intermediate ( $\mathbf{2}$, middle trace) and ingestive ( $\mathbf{C}$, bottom trace) biting motor programs (BMPs). $\boldsymbol{D}$, Plot of the mean protraction and retraction firing rates of $B 8$ during motor programs triggered by a specific stimulus (Red; $E N$ or $(B I-2$ ) after a specific recent history (Blue; Default, Post-EN or Post-CBI-2). B8 activity is intermediate in nature during EN or CBI-2 programs triggered in the default state. $\mathrm{B} 8$ activity is ingestive during $\mathrm{CBI}-2$ programs following other $\mathrm{CBI}-2$ programs. $\mathrm{B} 8$ activity is egestive during $\mathrm{CBI}-2$ programs following EN programs and during EN programs following $(\mathrm{BI}-2$ and EN programs. $\boldsymbol{E}$ and $\boldsymbol{F}$ are schematic diagrams of the

cerebral ganglion (Rosen et al., 1991; Hurwitz et al., 1999) and spiking CBI-2 at $10 \mathrm{~Hz}$ initiates protraction within a couple of seconds, and protraction lasts on average $20 \mathrm{~s}$ (Jing and Weiss, 2005).

Experimental protocols. CBI-2 motor programs were triggered by stimulating CBI-2 for the duration of protraction at $10 \mathrm{~Hz}$ with $15 \mathrm{~ms}$ DC pulses eliciting one-for-one action potentials (Friedman and Weiss, 2010). Single EN programs were triggered by shocking the posterior branch of the EN with $\sim 4-5 \mathrm{~V}$ for $3 \mathrm{~ms}$ at $2 \mathrm{~Hz}$ for the duration of protraction. CBI-2 priming was induced by triggering $10 \mathrm{CBI}-2$ programs with $30 \mathrm{~s}$ between the termination of retraction and the initiation of the following protraction. To test the effects of CBI-2 on B4/5, B8, and B65 excitability in HiDi, B4/5, $\mathrm{B} 8$, or B65 was injected with suprathreshold DC constant current pulses 5 times with a 1 min interstimulus interval. CBI-2 was then spiked at $10 \mathrm{~Hz}$, for $20 \mathrm{~s}$ with $30 \mathrm{~s}$ between each of 10 stimulus trains. The same amount of DC was then injected into B4/5, B8, or B65 every minute for 10 min to gauge any changes in excitability. For experiments in which B65 was bilaterally depolarized, we triggered multiple EN programs while depolarizing $\mathrm{B} 65$ to fire at a few different rates, as we could not know ahead of time the firing rate that B65 would achieve post-CBI-2 priming. For experiments in which B65 was bilaterally hyperpolarized, the hyperpolarizing current was gradually removed to avoid any rebound-evoked activity in B65. For the purpose of data analysis, we selected post hoc those EN motor programs in which B65s firing rate when depolarized was within $10 \%$ of the firing rate achieved by $\mathrm{B} 65$ post-CBI- 2 priming. For all bilateral impalement experiments, all Pre-CBI-2 values were calculated by averaging across the four programs triggered before CBI-2 priming as they did not differ statistically for any of the cells we examined (see Results).

For experiments on the effects of the CBI-2induced increase in B8 excitability on the B65

\section{$\leftarrow$}

neurons activated by the command-like interneuron $\mathrm{CBI}-2$ and EN (respectively) over the course of protraction (white) and retraction (black) and their inputs to each other and the motor neuron B8. Interneurons are grouped into either the ingestion or egestion promoting modules. $\boldsymbol{E}, \mathrm{CBI}-2$ activates the protraction interneuron B40 which suppresses B8 activity during protraction and promotes $\mathrm{B} 8$ activity during retraction. $\mathrm{CBI}-2 \mathrm{als} 0$ weakly activates the protraction interneuron B20 (represented by the smaller excitatory drive from $\mathrm{B} 20$ to $\mathrm{B} 8$ ). (BI-2 furthermore inhibits the egestion promoting protraction interneuron $\mathrm{B} 65$, which is in gray to indicate that it is not active in $\mathrm{CBI}-2$ programs. The inhibitory neurons B4/5 are activated at the switch to retraction and provide inhibitory input to $B 8$ during retraction. $\boldsymbol{F}$, Egestive motor programs are triggered by stimulating the EN. EN stimulation provides excitatory input to $B 65, B 20$ and B4/5. Because B65 and B20 provide excitatory drive to $B 8$ during protraction and $B 4 / 5$ provides inhibitory drive during retraction, B8 activity is higher in protraction phase relative to retraction phase. B40 is in gray as it is not active in EN motor programs. 
A

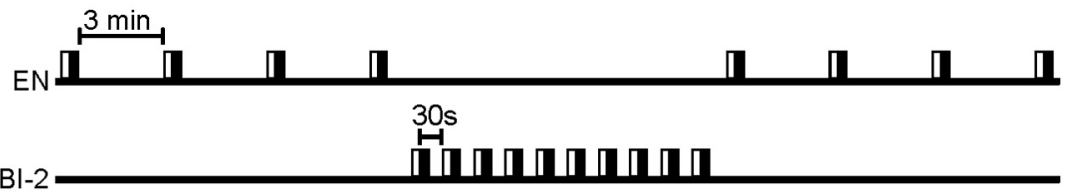

B
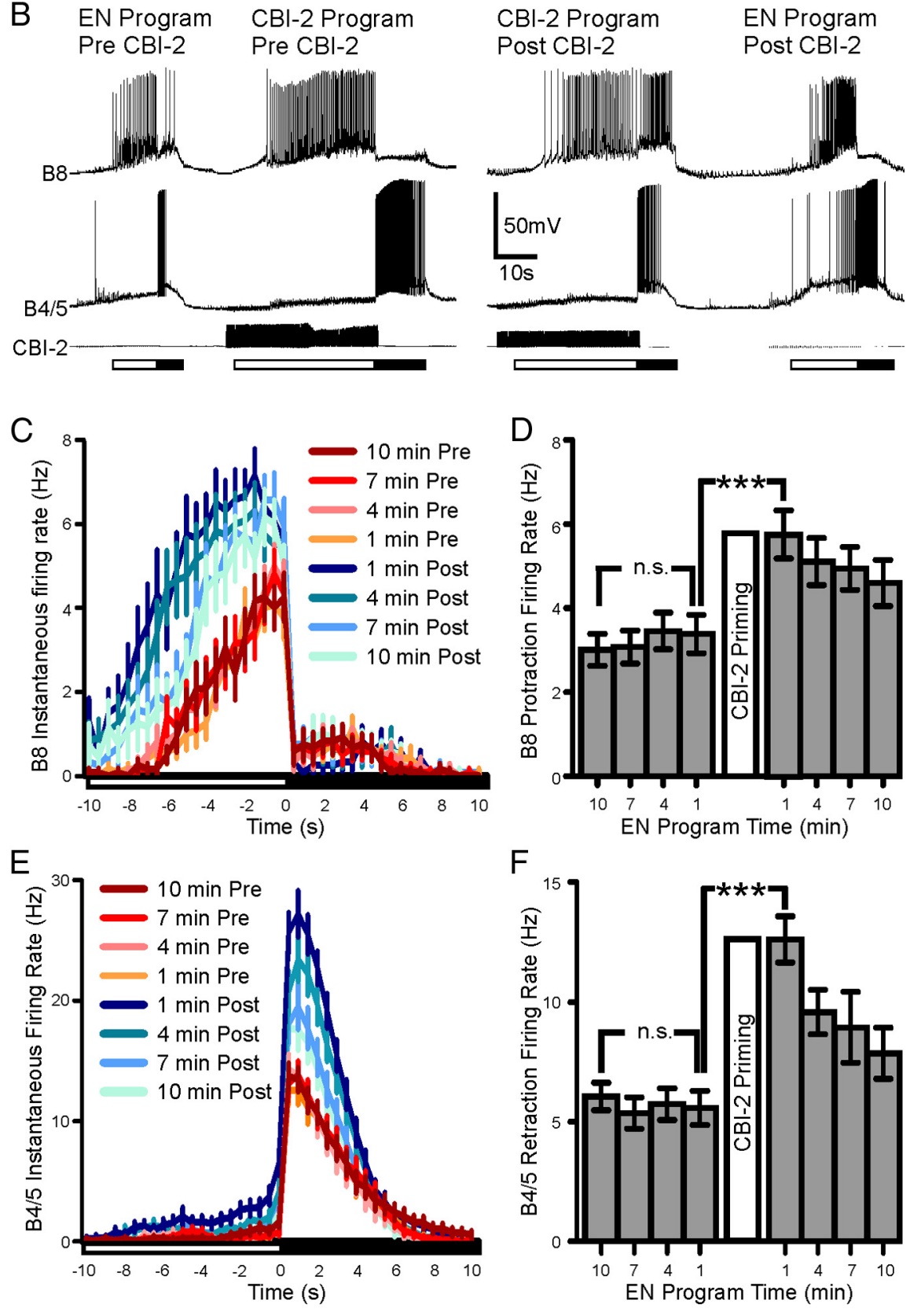

Figure 2. $\quad \mathrm{CBI}-2$ priming enhances the implementation of egestive motor programs. $\boldsymbol{A}$, Experimental protocol for positive biasing of EN programs by $\mathrm{CBI}-2$ priming. Four EN programs are triggered with a 3 min interprogram interval. Ten CBI-2 programs are elicited with $30 \mathrm{~s}$ between the beginning of retraction and the beginning of protraction. Four EN programs are then triggered with a 3 min interprogram interval. $\boldsymbol{B}$, Representative traces of positive biasing of egestive behavior. Initially EN stimulation elicits motor programs that are intermediate in nature. B8 activity is low across both protraction and retraction phases and B4/5 activity is low during retraction phase. After $\mathrm{CBI}-2$ priming, $\mathrm{B} 8$ activity increases during retraction and $\mathrm{B} 4 / 5$ retraction firing rate decreases. In EN programs triggered after $\mathrm{CBI}-2$ priming, B8 protraction activity increases as does B4/5 retraction activity. C, B8 Instantaneous firing rate $( \pm S E M)$ over protraction and retraction phase before (warm colors) and after (cool colors) CBI-2 priming. Time 0 indicates the switch from protraction to retraction. D, B8 average protraction firing rate in EN programs triggered 10, 7, 4 and $1 \mathrm{~min}$ before $\mathrm{CBI}-2$ priming and 1, 4, 7 and $10 \mathrm{~min}$ after (BI-2 priming $(n=27)$. $\boldsymbol{E}, \mathrm{B} 4 / 5$ instantaneous firing rate ( \pm SEM) over protraction and retraction phase before (warm colors) and after (cool colors) CBI-2 priming. Time 0 indicates the switch from protraction to retraction. $F, B 4 / 5$ retraction firing rate in $\mathrm{EN}$ motor programs triggered $10,7,4$ and 1 min before $C \mathrm{BI}-2$ priming and $1,4,7$, and 10 min after $\mathrm{CBI}-2$ priming $(n=30) .{ }^{* *} p<0.001$, n.S., not significant. to B8 EPSP we spiked B65 at $5 \mathrm{~Hz}$ for $10 \mathrm{~s}$ with a $90 \mathrm{~s}$ intertrain interval to establish a baseline number of spikes elicited from B8 in HiDi. We then induced CBI-2 priming (see above) and then repeated the $\mathrm{B} 65$ spike trains for $30 \mathrm{~min}$. To determine whether the amount of inward current evoked in B8 by B65 is affected by CBI-2, we used single-electrode voltage clamp to alternately clamp B8 at either $-55 \mathrm{mV}$ or $-70 \mathrm{mV}$, and repeated the $\mathrm{B} 65$ stimulation (as described above) before and after CBI-2 priming.

In neuropeptide occlusion experiments we first elicited a baseline number of spikes from B65 (Pre-CBI-2), induced the increase in B65 excitability with a single train of CBI-2 stimulation (Post-CBI-2) and allowed the preparation to recover (Recovery). We then bath applied $1 \mu \mathrm{M}$ FCAP and CP2, adjusted the amount of current injected into B65 to elicit the same number of spikes as before the peptide application and stimulated CBI-2 to determine whether CBI-2 could still increase B65 excitability. Finally, we washed out the peptides for $45 \mathrm{~min}$ and then induced the increase in B65 excitability by CBI-2 to demonstrate that the excitability of $\mathrm{B} 65$ could be repeatedly enhanced.

\section{Results}

The priming of ingestive behavior enhances the egestive characteristics of motor responses

To monitor the effects of CBI-2 priming on network output during EN and CBI-2 motor programs, we recorded the activity of radula closure neuron $\mathrm{B} 8$ and the inhibitory neurons B4/5 which provide inhibitory input to B8 during retraction. The EN was stimulated to trigger four motor programs with sufficient time between programs (3 min) to avoid egestive priming, thus providing a probe for the baseline state of the network. CBI-2 was then repeatedly stimulated, and this was followed by four EN programs triggered with a 3 min interprogram interval (Fig. $2 A$ ). Initial EN programs were intermediate as the firing rate of $\mathrm{B} 8$ was low during protraction and retraction and $\mathrm{B} 4 / 5$ was moderately active during retraction. CBI-2 priming was then induced (see Materials and Methods) and final CBI-2 programs were highly ingestive with $\mathrm{B} 8$ retraction firing rate increased and $\mathrm{B} 4 / 5$ retraction firing rate decreased (Fig. 2B). Conversely, EN programs following CBI-2 priming were strongly egestive, with the protraction-phase firing rate of $\mathrm{B} 8$ and the retraction-phase firing rate of B4/5 dramatically increased (Fig. 2B). Both the peak (Fig. $2 C ; t=6.725 ; \mathrm{df}=26$; $p<0.0001 ; n=27$ ) and the mean (Fig. $\left.2 D ; F_{(7,175)}=24.89 ; p<0.001 ; n=27\right)$ protraction firing rates of $\mathrm{B} 8$ were signifi- 

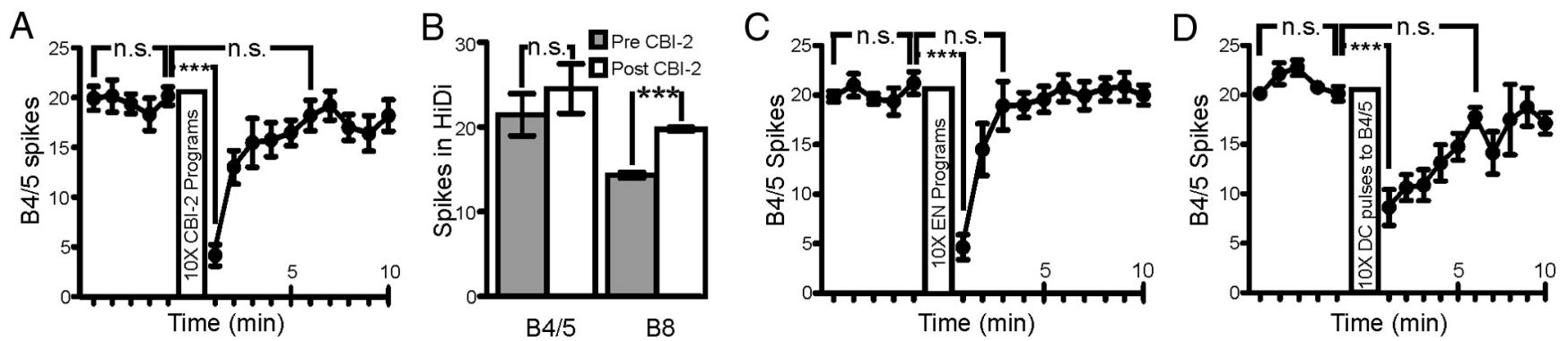

Figure 3. B4/5 excitability decreases briefly after repeated motor programs, but is not directly modulated by CBI-2.A, B4/5 excitability (measured as number of spikes elicited by suprathreshold DC constant current pulses; see Materials and Methods) drops immediately after (BI-2 priming and returns to baseline levels within 5 min $(n=13)$. $B$, B4/5 excitability is not affected by CBI-2 stimulation in HiDi, while B8 excitability is increased $(n=6)$. C, B4/5 excitability drops immediate after repeated EN programs and recovers within 3 min $(n=16)$. D, B4/5 excitability drops immediate after receiving repeated $10 \mathrm{~s} D C$ injections and recovers within $6 \min (n=8) .{ }^{* * *} p<0.001$, n.S., not significant.

A

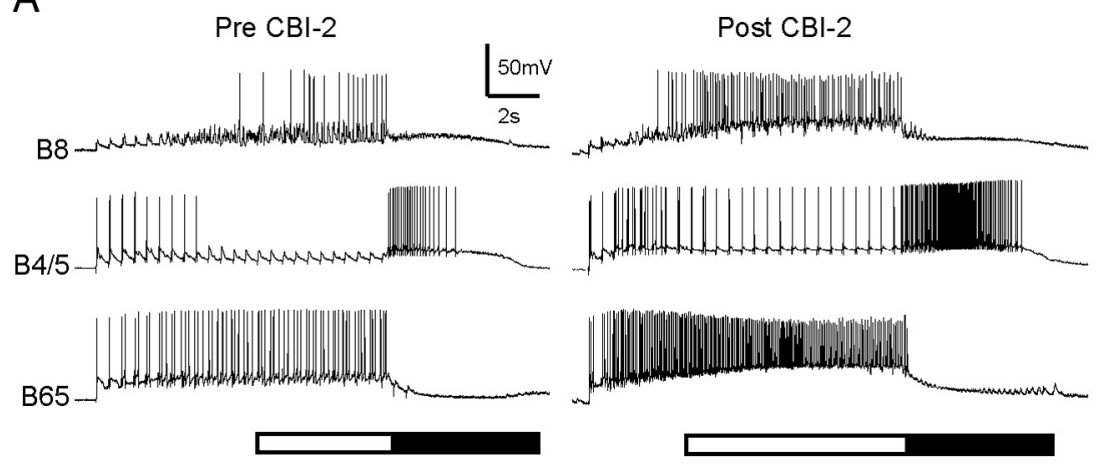

B

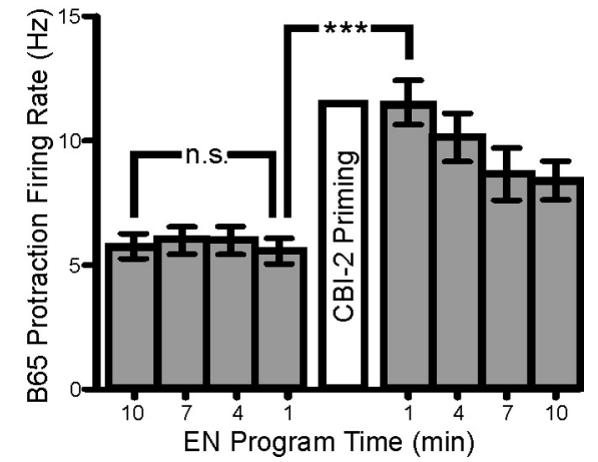

Figure 4. B65 activity in EN programs increases after CBI-2 priming. $A$, Representative trace of $\mathrm{B} 8, \mathrm{~B} 4 / 5$ and $\mathrm{B} 65$ activity during EN programs before (Pre-CBI-2) and after (Post-CBI-2) $\mathrm{CBI}-2$ priming. $B$, B65 protraction firing rate in EN motor programs triggered $10,7,4$ and 1 min before $C B I-2$ priming and $1,4,7$ and 10 min after $C B I-2$ priming. $B 65$ protraction firing rate increases significantly after $\mathrm{CBI}-2$ priming $(n=13){ }^{* * *} p<0.001$, n.S., not significant.

cantly higher in EN programs following CBI-2 priming. Furthermore, both the peak (Fig. $2 E$; values \pm SEM: $14.14 \pm 1.2 \mathrm{~Hz}$ to $30.14 \pm 1.6 \mathrm{~Hz} ; t=9.097 ; \mathrm{df}=29 ; p<0.001 ; n=30)$ and mean (Fig. $\left.2 F ; F_{(7,203)}=42.84 ; p<0.001 ; n=30\right) \mathrm{B} 4 / 5$ retraction firing rates in EN programs were also significantly higher following CBI-2 priming. Thus, the network state induced by CBI-2 priming enhances two incompatible responses that involve overlapping sets of neurons: ingestive responses triggered by CBI-2 and egestive responses triggered by the EN.

The effect of CBI-2 priming on B4/5 participation in EN programs was not due to an increase in B4/5 excitability, as B4/5 excitability (measured as number of spikes elicited by suprathreshold DC constant current pulses; see Materials and Methods) decreased significantly after $\mathrm{CBI}-2$ priming (Fig. $3 A$; one-way ANOVA; $F_{(3,36)}=66.32 ; p<0.001 ; n=13$ ). This decrease did not appear to be caused directly by CBI-2 as spiking CBI-2 in HiDi saline for the same duration as during the CBI-2-induced priming experiments described above did not affect B4/5 excitability (Fig. $3 B ; t=1.716 ; \mathrm{df}=5 ; p=0.1468 ; n=6$ ). However, as reported previously (Dacks et al., 2012), CBI-2 stimulation in HiDi did increase B8 excitability $(t=12.31$; df $=5$; $p<0.001$; $n=6$ ), indicating that in these preparations CBI-2 was capable of modulating neuronal excitability. The decrease in B4/5 excitability was likely due to their activity during motor programs as we found that $\mathrm{B} 4 / 5$ excitability decreased after repeated $\mathrm{EN}$ programs (Fig. $3 C$; one-way ANOVA; $F_{(3,45)}=38.4 ; p<0.001 ; n=$ 16) and after spiking elicited by repeated $10 \mathrm{~s}$ DC injections to B4/5 (Fig. 3D; one-way ANOVA; $F_{(4,36)}=39.61 ; p<0.001 ; n=$ $8)$. Thus, the increase in B4/5 activity in EN programs after CBI-2 priming (Fig. 2E,F) was likely not due to changes in the intrinsic properties of $\mathrm{B} 4 / 5$, but rather to changes in the synaptic input that $\mathrm{B} 4 / 5$ received during $\mathrm{EN}$ programs.

\section{$\mathrm{CBI}-2$ priming increases the activity of $\mathrm{B} 65$, an egestion-promoting neuron}

Two observations suggested that interneuron B65 could enhance the egestive characteristics of EN-elicited motor programs following CBI-2 priming. First, B65 enhances the retraction firing rate of $\mathrm{B} 4 / 5$ by inducing a preparatory depolarization during protraction phase (Kabotyanski et al., 1998) and B65 provides excitatory drive to B8 during protraction both directly (Due et al., 2004; Díaz-Ríos and Miller, 2005) and via B20 (Jing and Weiss, 2001). Second, B65 is preferentially active in EN programs (Proekt et al., 2007) as it is directly inhibited by CBI-2 (Jing and Weiss, 2005). Thus, if CBI-2 prestimulation were to up-modulate $\mathrm{B} 65$, this effect would only be evident when B65 is activated in EN-elicited motor programs. Consistent with this possibility, we found that B65 activity in EN-elicited programs was significantly increased after CBI-2 priming (Fig. $4 A, B$; one-way ANOVA; $\left.F_{(7,84)}=32.98 ; p<0.001 ; n=13\right)$.

To determine the extent to which the increase in B65 activity contributes to the changes in EN-elicited programs following CBI-2 priming, we performed two sets of experiments in which we used DC injections to manually manipulate the spiking activity of both B65s under visual inspection to either mimic B65s pre-priming activity in the primed state or to mimic B65 postpriming activity before CBI-2 priming (see Materials and Methods). In the first set of experiments we induced CBI-2 priming, 
A
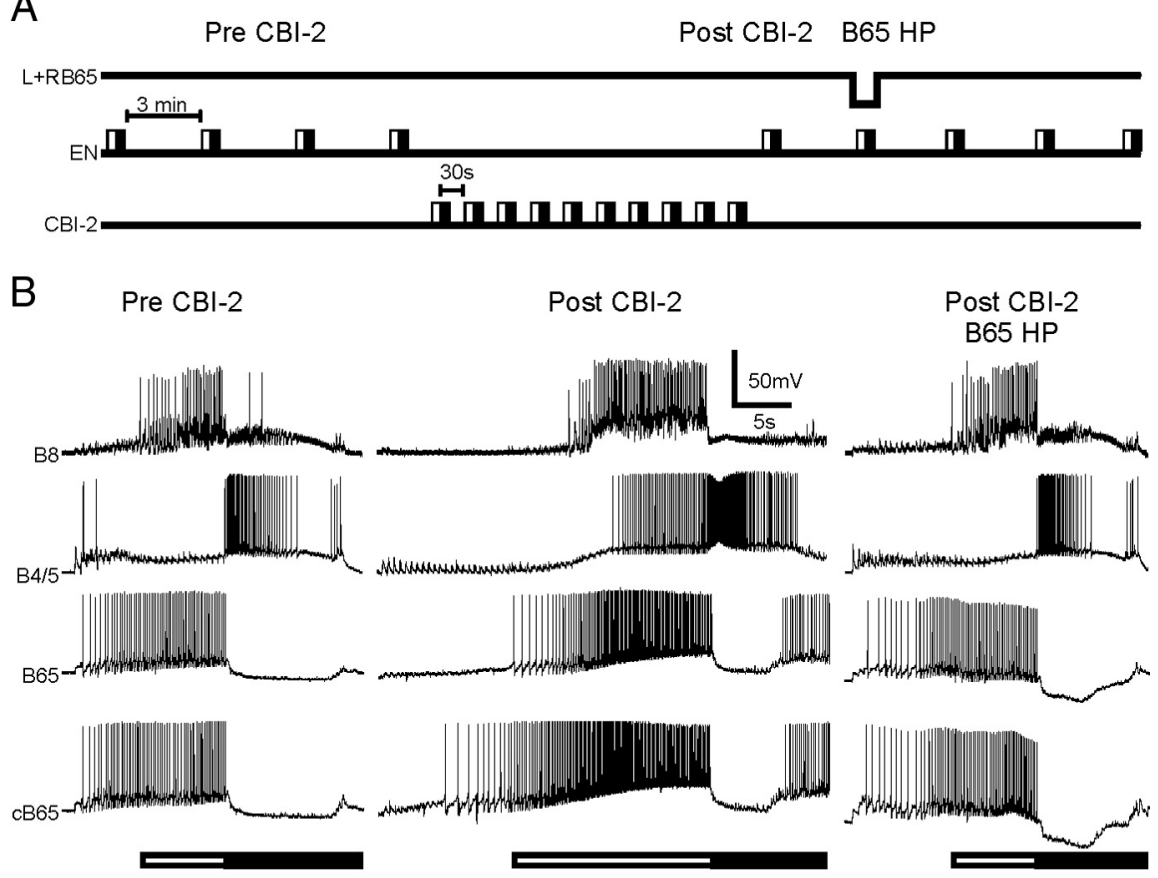

C
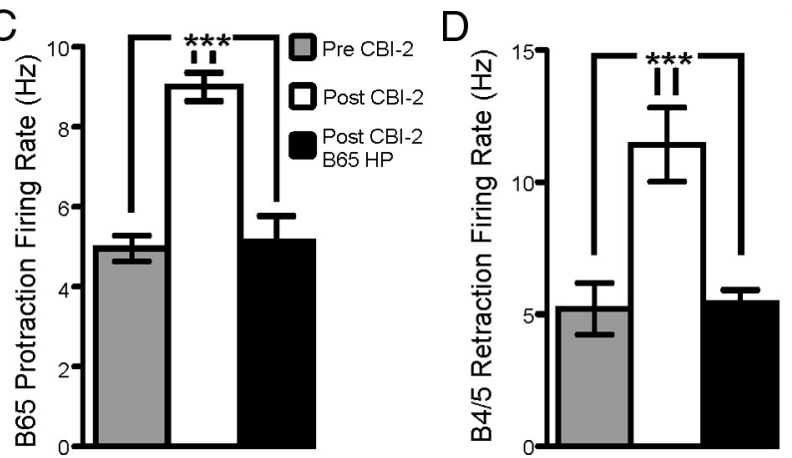

$E$

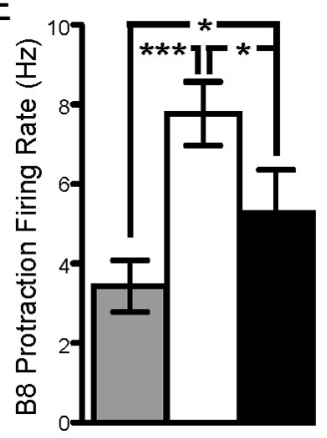

Figure 5. The increase in B65 activity in EN programs is necessary for the positive biasing of B4/5 activity and contributes to the increase in B8. A, Experimental protocol for determining the contribution of B65 to the positive biasing of B4/5 and B8 in EN programs. Four EN programs are triggered with a 3 min interprogram interval (Pre-CBI-2). Ten CBI-2 programs are elicited with $30 \mathrm{~s}$ between the beginning of retraction and the beginning of protraction. A single EN program is triggered (Post-CBI-2) followed by another EN program 3 min later in which both B65s are injected with sufficient hyperpolarizing current to return their protraction firing rate to pre-CBI-2 priming levels (Post- $\mathrm{CBI}-2 \mathrm{~B} 65 \mathrm{HP}$ ). The hyperpolarizing current is removed and three more EN programs are then triggered with a 3 min interprogram interval. $B$, Representative trace of $B 8, B 4 / 5$ and both $B 65$ s activity during EN programs before $\mathrm{CBI}-2$ priming (Pre-CBI-2), after $\mathrm{CBI}-2$ priming (Post-CBI-2) and after $\mathrm{CBI}-2$ priming with bilateral hyperpolarization of $\mathrm{B} 65$ (Post-CBI-2 B65 HP). C, B65 protraction firing rate before (BI-2 priming (Pre-CBI-2; gray), after CBI-2 priming (Post-CBI-2; white) and during bilateral hyperpolarization after $\mathrm{CBI}-2$ priming (Post-CBI-2 B65 HP; black). B65 protraction firing rate was significantly higher after $\mathrm{CBI}-2$ priming and bilaterally hyperpolarizing both $\mathrm{B} 65$ s decreased $\mathrm{B} 65$ s firing rate to levels that were not significantly different from pre-priming levels $(n=8)$. D, B4/5 retraction firing rate before (BI-2 priming (Pre-CBI-2; gray), after CBI-2 priming (Post-CBI-2; white) and during bilateral hyperpolarization after CBI-2 priming (Post-CBI-2 B65 HP; black). B4/5 retraction firing rate was significantly higher after $\mathrm{CBI}-2$ priming and bilaterally hyperpolarizing both $\mathrm{B} 65$ s decreased $\mathrm{B} 4 / 5$ firing rate to levels that were not significantly different from pre-priming levels $(n=8)$. $\boldsymbol{E}$, B8 protraction firing rate before (BI-2 priming (Pre-CBI-2; gray), after (BI-2 priming (Post-CBI-2; white) and during bilateral hyperpolarization after (BI-2 priming (Post-CBI-2 B65 HP; black). B8 protraction firing rate was significantly higher after $\mathrm{CBI}-2$ priming, but bilaterally hyperpolarizing $\mathrm{B} 65$ did not decrease $\mathrm{B} 8$ firing rate to pre-priming levels $(n=7)$ ) ${ }^{*} p<0.05,{ }^{* * *} p<0.001$.

and then injected hyperpolarizing current into both B65s to adjust their firing rate under visual control to near pre-CBI-2 priming levels. The purpose of this set of experiments was to determine whether $\mathrm{B} 4 / 5$ and $\mathrm{B} 8$ activity in EN programs would also return to pre-CBI-2 levels (Fig. $5 A$ ). Figure $5 B$ depicts representative recordings from $\mathrm{B} 8, \mathrm{~B} 4 / 5$, and both $\mathrm{B} 65$ s during this experiment. The protraction firing rate of $\mathrm{B} 8$ and $\mathrm{B} 65$ and the retraction firing rate of $\mathrm{B} 4 / 5$ increased in $\mathrm{EN}$ programs following
CBI-2 priming (Pre-CBI-2 vs Post-CBI-2 in Fig. 5B). Bilateral hyperpolarization of B65 (Post-CBI-2 B65 HP) decreased B65 protraction firing rate back to prepriming levels (Fig. $5 C$; one-way ANOVA; $\left.F_{(2,14)}=19.71 ; p<0.001 ; n=8\right)$. Furthermore $\mathrm{B} 4 / 5$ retraction firing rate in $\mathrm{EN}$ elicited motor programs in which both B65s were hyperpolarized also decreased back to pre-priming levels (Fig. 5D; oneway ANOVA; $F_{(2,14)}=25.33 ; p<0.001$; $n=8)$. However, while bilateral hyperpolarization of B65 significantly decreased B8 firing rate (Fig. $5 E$; one-way ANOVA; $\left.F_{(2,12)}=9.02 ; p<0.05 ; n=7\right)$, B8 firing rate was still significantly higher than prepriming levels. This suggests that while B65 contributes to the elevation of B8 firing rate in $\mathrm{EN}$ programs that were elicited following CBI-2 priming, there is likely an additional contributing mechanism.

In the second set of experiments an EN program was triggered before CBI-2 priming in which depolarizing current was injected into both B65s (Pre-CBI-2 B65 DP) to adjust their firing rate under visual control to achieve approximately the protraction firing rate observed after priming in other preparations (Fig. $4 B$; see Materials and Methods). This simulated the increase in B65 activity without inducing any other changes associated with CBI-2 priming and allowed us to determine whether the increased B65 activity was sufficient to induce the increase in B8 and B4/5 activity (Fig. 6A). Figure $6 B$ depicts representative recordings from $\mathrm{B} 8, \mathrm{~B} 4 / 5$, and both B65s in this experiment. A one-way ANOVA confirmed that the mean B65 firing rate achieved when both $\mathrm{B} 65$ s were depolarized was significantly higher than before CBI-2 priming but not significantly different from the B65 firing rate achieved in EN programs post-CBI-2 priming (Fig. $6 \mathrm{C}$; one-way ANOVA; $F_{(2,10)}=10.64 ; p<0.001 ; n=$ 6). Depolarizing both B65s also increased B4/5 firing rate (Fig. $6 D$; one-way ANOVA; $\left.F_{(2,10)}=13.75 ; p<0.01 ; n=6\right)$ to a level similar to that achieved by $\mathrm{B} 4 / 5$ after CBI-2 priming. These data, in combination with the bilateral hyperpolarization experiments, suggest that the increase in B65 activity accounts for the increase in B4/5 activity in EN programs after CBI-2 priming. However, the protraction firing rate of B8 was significantly higher after CBI-2 priming compared with either before CBI-2 priming or EN programs in which both B65s were depolarized (Fig. 6E; one-way ANOVA; $\left.F_{(2,10)}=18.41 ; p<0.001 ; n=6\right)$. Again, this suggested that while the increase in $\mathrm{B} 65$ activity contributes to the increase of B8 protraction firing rate after CBI-2 priming, there must be an additional mechanism. 
CBI-2 priming increases B8 excitability (Dacks et al., 2012) which could serve as an additional contributing factor to the increased $\mathrm{B} 8$ protraction firing rate in $\mathrm{EN}$ programs. Consistent with this, the number of spikes elicited from B8 during $10 \mathrm{~s}$ of $5 \mathrm{~Hz}$ B65 spiking increased post-CBI-2 priming (Fig. $7 A, B$; one-way ANOVA; $\left.F_{(3,9)}=24.22 ; p<0.001 ; n=4\right)$ and the latency to the first B8 spike decreased (Fig. $7 C$; one-way ANOVA; $F_{(3,9)}=12.35 ; p<$ $0.01 ; n=4)$. While CBI-2 priming caused B8 resistance to increase from 3.9 to 5.9 $\mathrm{M} \Omega$, CBI-2 priming did not affect the amount of leak subtracted current evoked in $\mathrm{B} 8$ by $\mathrm{B} 65$ when $\mathrm{B} 8$ was clamped via a single-electrode voltage clamp at either $-55 \mathrm{mV}$ (Fig. $7 D ; t=0.3807 ; \mathrm{df}=3 ; p=$ $0.7288 ; n=4$ ) or $-70 \mathrm{mV}$ (Fig. $7 D ; t=$ $0.484 ; \mathrm{df}=3 ; p=0.6615 ; n=4)$. Furthermore, there was no effect of CBI-2 priming on the EPSP height evoked by B65 in B4/5 (Fig. $7 E$; one-way ANOVA; $F_{(2,14)}=$ $0.2498 ; p=0.7823 ; n=8)$, suggesting that the change in the influence of B 65 on B4/5 firing rate in EN-elicited motor programs is not likely due to a synaptic change. These data therefore do not suggest the involvement of synaptic plasticity, but rather suggest that the increase in $\mathrm{B} 8 \mathrm{ex}-$ citability and the increase in B65 firing rate both contribute to the increase in $\mathrm{B} 8$ protraction firing rate in EN programs after CBI-2 priming.

\section{CBI-2 directly enhances B65 excitability} via peptidergic modulation

CBI-2 directly modulates the excitability of several neurons in the buccal ganglion and was therefore a logical candidate to enhance the activity of $\mathrm{B} 65$ in EN programs. We therefore tested whether CBI-2 directly affected B65 excitability. In HiDi, constant current pulses were injected into B65 to establish baseline excitability and were then interleaved with $20 \mathrm{~s}$ of $10 \mathrm{~Hz}$ CBI-2 stimulation mimicking CBI-2 activity during protraction phase. After just one train of CBI-2 stimulation, B65 excitability increased and typically recovered within 10-15 min (Fig. 8A). After 10 trains (as occurs in a bout of CBI-2 priming) the number of spikes elicited from B65 increased by $118 \%$ and recovered within $35 \mathrm{~min}$ (Fig. $8 B$; one-way ANOVA; $F_{(2,10)}=47.46 ; p<$ $0.001, n=6)$. Furthermore, the latency to first B65 spike decreased significantly (one-way ANOVA; $F_{(2,10)}=28.5 ; p<0.001$; $n=6)$ from $621.4 \mathrm{~ms}[ \pm 82(\mathrm{SEM})]$ to $107.7 \mathrm{~ms}( \pm 17)$ and recovered back to $674.1 \mathrm{~ms}( \pm 151)$. These data suggest that CBI-2 directly enhances the excitability of B65.

CBI-2 contains the neuropeptides FCAP and CP2 (Koh et al., 2003) which generate feeding behavior in the buccal ganglion and enhance the excitability of several neurons in the feeding nervous
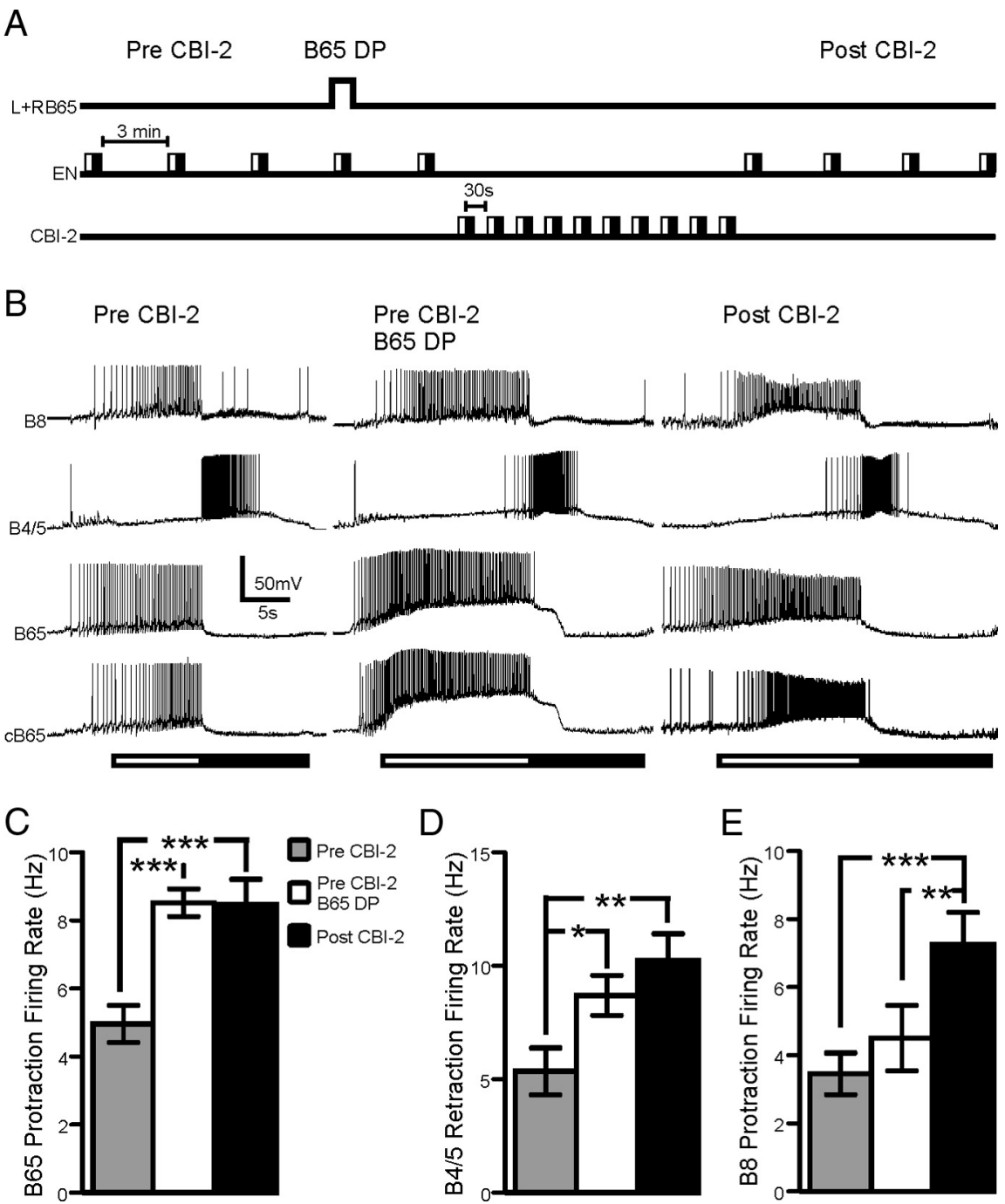

Figure 6. The increase in B65 activity in EN programs is sufficient to positively bias B4/5 activity, but not B8. A, Second experimental protocol for determining the contribution of $B 65$ to the positive biasing of $B 4 / 5$ and $B 8$ in EN programs. Three EN programs are triggered with a 3 min interprogram interval (Pre-CBI-2). A single EN program is triggered in which both $\mathrm{B} 65 \mathrm{~s}$ are depolarized to spike at approximately twice the rate observed in the initial three EN programs (Pre-CBI-2 B65 DP). A fourth baseline EN program is then triggered. Ten $\mathrm{CBI}-2$ programs are elicited with 30 s between the beginning of retraction and the beginning of protraction. Four EN programs are then triggered with a 3 min interprogram interval (Post-CBI-2). B, Representative trace of B8, B4/5 and both B65s activity during EN programs before $\mathrm{CBI}-2$ priming (Pre-CBI-2), before $\mathrm{CBI}-2$ priming with both $\mathrm{B} 65$ s depolarized (Pre-CBI-2 B65 DP) and after CBI-2 priming (Post-CBI-2). C, B65 protraction firing rate before (BI-2 priming (Pre-CBI-2; gray), before (BI-2 priming with both B65s depolarized (Pre-CBI-2 B65 DP; white) and after (BI-2 priming (Post-CBI-2; black). B65 protraction firing rate was significantly increased after $\mathrm{CBI}-2$ priming and bilaterally depolarizing both $\mathrm{B} 65$ s pre-CBI-2 priming increased B65 firing rate to levels that were not significantly different from post-priming levels $(n=6)$. $D, B 4 / 5$ retraction firing rate before (BI-2 priming (Pre- (BI-2; gray), before CBI-2 priming with both B65s depolarized (Pre-CBI-2 B65 DP; white) and after CBI-2 priming (Post-CBI-2; black). B4/5 retraction firing rate significantly increased in EN motor programs in which both $\mathrm{B} 65 \mathrm{~s}$ were depolarized. The firing rate of $B 4 / 5$ was not significantly different from the levels achieved in EN programs after CBI-2 priming $(n=$ 6). $\boldsymbol{E}$, B8 protraction firing rate before (BI-2 priming (Pre-CBI-2; gray), before CBI-2 priming with both B65s depolarized (Pre-CBI-2 B65 DP; white) and after (BI-2 priming (Post-CBI-2; black). B8 protraction firing rate was not significantly affected by bilateral depolarization of B65 during EN motor programs $(n=6)$. ${ }^{*} p<0.05,{ }^{* *} p<0.01,{ }^{* * *} p<0.001$.

system of Aplysia (Sweedler et al., 2002; Koh et al., 2003; Koh and Weiss, 2005, 2007; Friedman and Weiss, 2010). We therefore sought to determine whether these two peptides modulated B65 excitability. At $1 \mu \mathrm{M}, \mathrm{FCAP}$ and $\mathrm{CP} 2$ increased the number of spikes elicited from B65 (Fig. $9 A$ ) by $\sim 60 \%$ (Fig. $9 B$; one-way ANOVA; $\left.F_{(2,16)}=83.55 ; n=9\right)$. Furthermore, the latency to first B65 spike decreased significantly (one-way ANOVA; $F_{(2,16)}=$ 28.23; $p<0.001 ; n=9)$ from $588.7 \mathrm{~ms}( \pm 53)$ to $346.8 \mathrm{~ms}( \pm 48)$ and recovered back to $643.0 \mathrm{~ms}( \pm 79)$. To determine whether the 

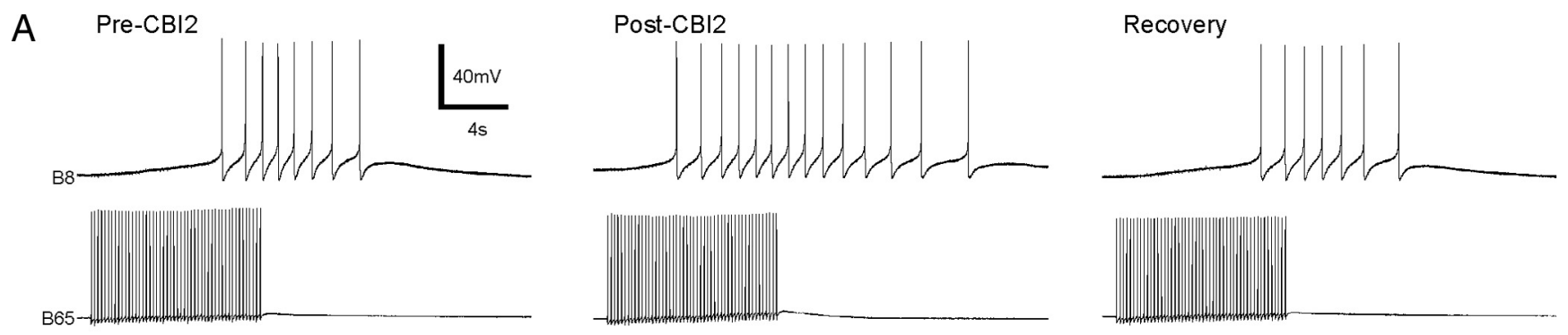

$\mathrm{B}$

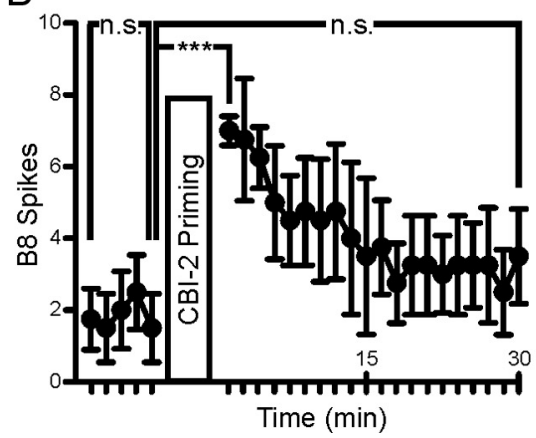

C

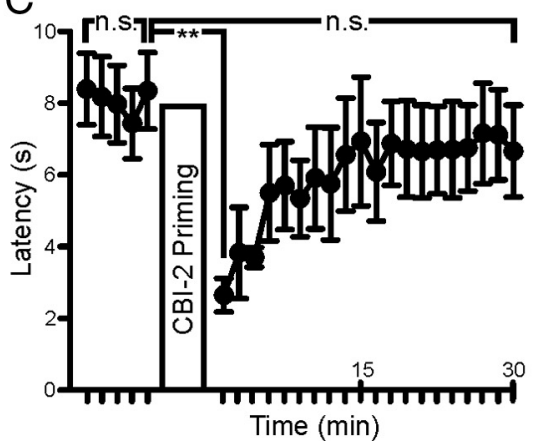

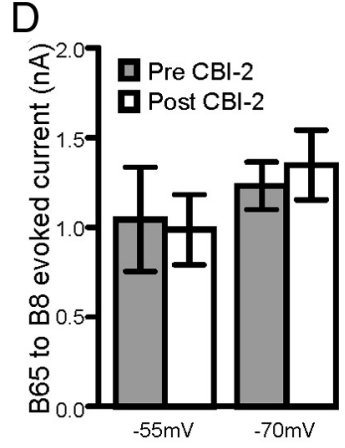

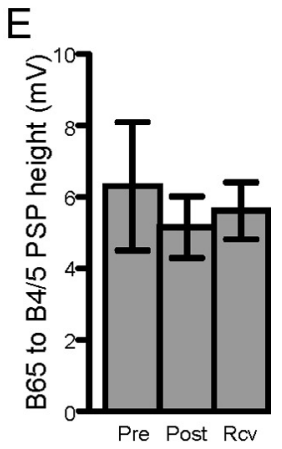

Figure 7. The (BI-2 priming-induced increase in B8 excitability enhances the response of B8 to B65 spiking. $A$, Representative trace of $\mathrm{B} 8$ activity during a 10 s $5 \mathrm{~Hz}$ train of $\mathrm{B} 65$ spiking in HiDi before (Pre-CBI-2), immediately after (Post-CBI-2) and 30 min after (Recovery) repeated (BI-2 stimulation. $\boldsymbol{B}$, The number of spikes elicited from B8 during each B65 spike train increases after repeated CBI-2 stimulation and recovers back to baseline $(n=4)$. C, The latency to first B8 spike during each B65 spike train decreases after repeated CBI-2 stimulation and recovers back to baseline $(n=4)$. D, The leak-subtracted maximal current evoked by 10 s of $5 \mathrm{~Hz}$ B65 spiking when B8 is clamped at either $-55 \mathrm{mV}$ or $-70 \mathrm{mV}$ is unaffected by $\mathrm{CBI}-2$ stimulation ( $n=4)$. E, The EPSP amplitudes (in mV) elicited by B65 in B4/5 did not differ before (pre), immediately after (post) or 15 min after (Rcv) CBI-2 priming $(n=8) .{ }^{* *} p<0.01$, ${ }^{* * *} p<0.001$, n.s., not significant.

\section{A}

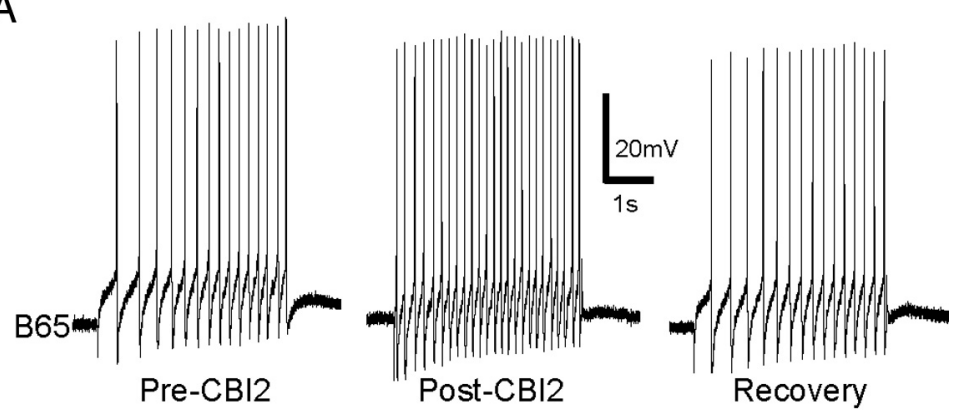

B

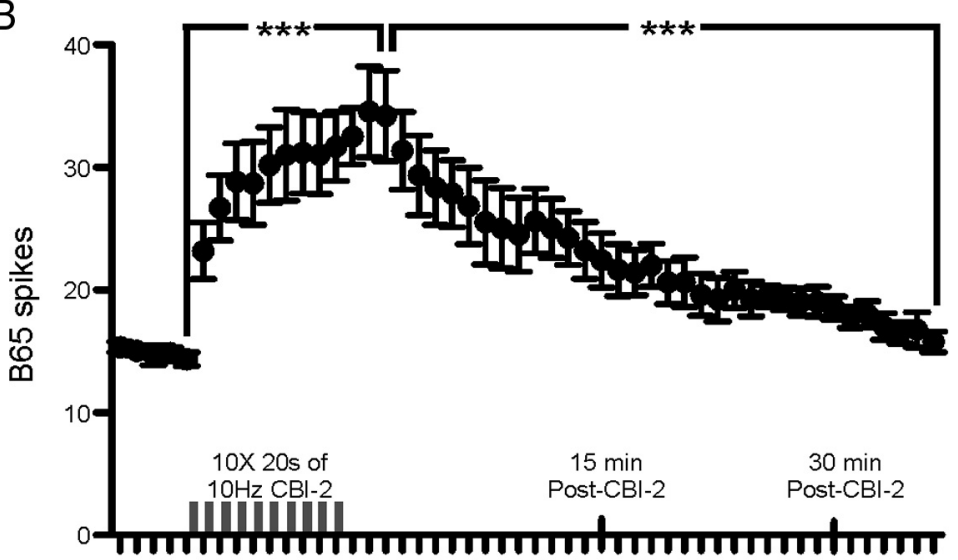

Time (min)

Figure 8. $\quad$ BI-2 enhances $B 65$ excitability. $A, A 4 s$ constant current pulse to $B 65$ elicits more spikes after a single 20 s train of 10 $\mathrm{Hz} \mathrm{CBI}-2$ spiking. $\boldsymbol{B}$, The number of spikes elicited from $\mathrm{B} 65$ increases after each of ten $20 \mathrm{~s}$ trains of $10 \mathrm{~Hz} \mathrm{CBI}-2$ spiking and remains elevated for $35 \min (n=6) .{ }^{* *} p<0.01$, n.s., not significant.
CBI-2-induced increase of B65 excitability affected the same cellular targets as FCAP and CP2, we performed an occlusion experiment to test whether CBI-2 could enhance $\mathrm{B} 65$ excitability in the presence of the two neuropeptides (Fig. 9C). A single train of CBI-2 stimulation was able to significantly enhance the excitability of B65 (Fig. 9D; one-way ANOVA; $F_{(8,32)}=$ 17.13; $p<0.001 ; n=5)$; however, in the presence of $1 \mu \mathrm{M}$ FCAP and CP2, CBI-2 stimulation did not affect B65 excitability. Furthermore, the ability of CBI-2 to enhance B65 excitability recovered after washout of the peptides (Fig. 9D). Thus, CBI-2 increases B65 excitability and, consequently, B65 protraction firing rate in EN motor programs, likely via the actions of FCAP/CP2. Notably, the modulation of $\mathrm{B} 65$ by CBI-2 remains latent as $\mathrm{B} 65$ is not active during CBI-2 motor programs and therefore the effects of CBI-2 on B65 are not apparent unless $\mathrm{EN}$ programs are triggered.

\section{Discussion}

The intrinsic properties and synaptic efficacies of neuronal network elements form the basis of network states. Consequently, network states often only manifest themselves as alterations of responses to the same stimulus. In this study, we examined the mechanisms that allow one network state 


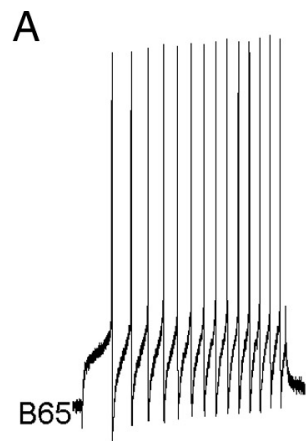

Control

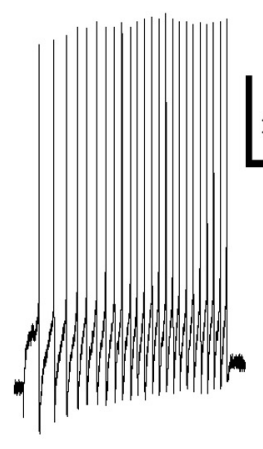

$1 \mathrm{uM} \mathrm{FCAP+CP2}$

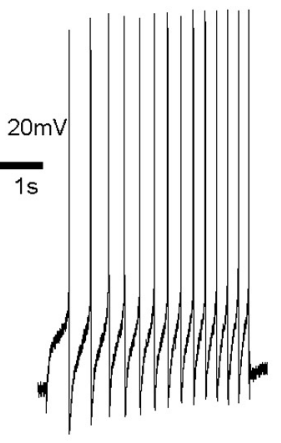

Wash
B

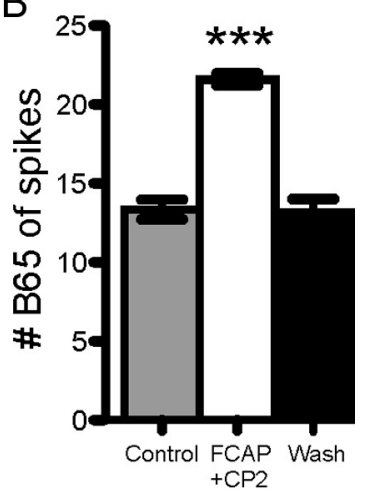

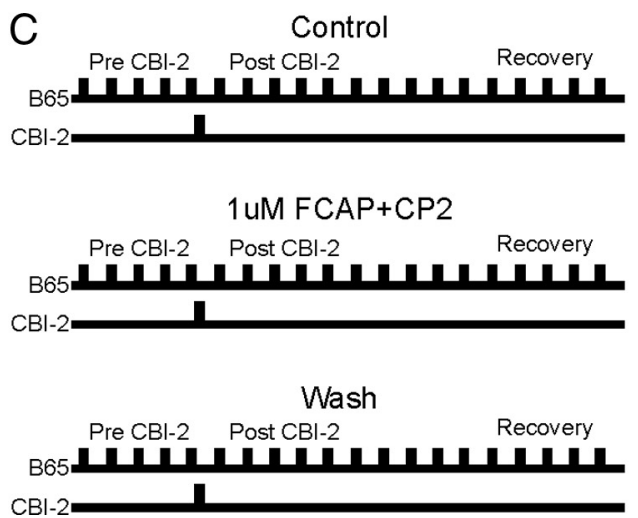

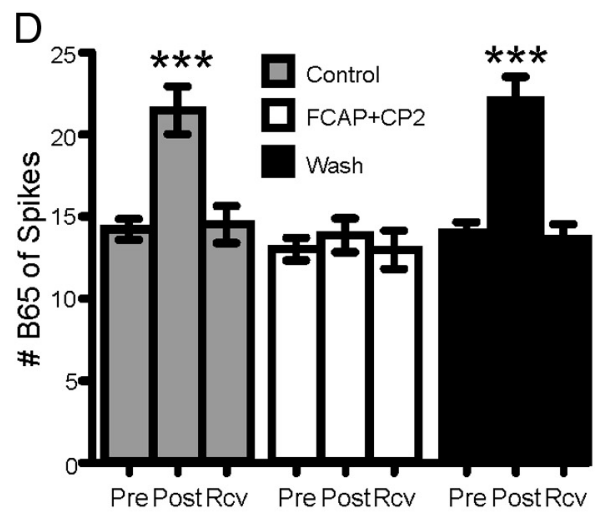

Figure 9. FCAP and CP2 enhance B65 excitability and occlude the effects of CBI-2 on B65 excitability. $A, A 4 s$ constant current pulse to B65 elicits more spikes in the presence of $1 \mu \mathrm{m} F C A P$ and CP2. B, The number of spikes elicited from B65 by a $4 \mathrm{~s}$ constant current pulse significantly increases in $1 \mu \mathrm{m} \mathrm{FCAP} \mathrm{and} \mathrm{CP2}(n=9)$. C, Experimental protocol for the occlusion of the effects of CBI-2 on B65 excitability by FCAP and CP2. B65 baseline excitability is probed with 4s constant current pulses to B65 separated by 1 min (Pre-CBI-2). Immediately after the fifth constant current pulse, CBI-2 is spiked at $10 \mathrm{~Hz}$ for $20 \mathrm{~s}$. B65 excitability continues to be tested for $15 \mathrm{~min}$ after the single train of (BI-2 stimulation (Control). The first 5 constant current pulses to B65 after (BI-2 stimulation are used to measure the effects of $\mathrm{CBI}-2$ on B65 excitability (Post-CBI-2) and the final five constant current pulses are used to measure the return of B65 excitability to baseline (Recovery). FCAP (1 $\mu \mathrm{M}$ ) and $C P 2$ are superfused onto the preparation and the same experimental protocol is implemented as during the control phase with the exception that the level of current injected into B65 is first adjusted to elicit the same number of baseline spikes as the control treatment $(1 \mu \mathrm{M}$ FCAP $+(P 2)$. The peptides are then washed out and the experimental protocol from the control treatment is repeated (Wash). D, CBI-2 stimulation significantly increases B65 excitability in the control and wash phases, but does not affect B65 excitability in the presence of $1 \mu \mathrm{m} F C A P$ and $C P 2(n=5)$. Pre $=$ Pre-CBI-2 stimulation, Post $=$ Post-CBI-2 stimulation, Rcv $=$ Recovery. ${ }^{* * *} p<0.001$, n.s., not significant.

to promote two antagonistic outputs in response to different stimuli. Repeated stimulation of CBI-2 induces a network state that enhances both ingestive responses to subsequent CBI-2 stimulation (Proekt et al., 2004) and egestive responses to EN stimulation (Proekt et al., 2008). We found that the enhancement of egestive responses is accomplished via modulation of $\mathrm{B} 65$, a neuron that belongs to the egestion-promoting module. $\mathrm{B} 65$ is actively suppressed during $\mathrm{CBI}-2$ programs and thus the enhancement of $\mathrm{B} 65$ excitability by $\mathrm{CBI}-2$ represents a latent modulation that remains masked until the appropriate stimulus (i.e., EN stimulation) is encountered. In this manner, a network state is established in which specific responses are enhanced without interfering with the implementation of antagonistic responses.

A growing body of work has demonstrated that the nervous system is modularly organized. Groups of neurons (called modules) that implement distinct components of a response are activated in different combinations and sequences to generate specific behaviors (Bizzi et al., 1991; Kiehn and Kjaerulff, 1998; Berkowitz, 2002a; Jing and Weiss, 2002; d'Avella et al., 2003; Jing et al., 2004; Jing and Weiss, 2005; Grillner, 2006), affording single networks the flexibility to generate diverse outputs (Briggman and Kristan, 2008). Often, the establishment of a network state alters the influence of one module at the expense of other antagonistic modules. For instance, in the buccal ganglion, neuron B20 (a member of the egestive module) is active across both EN and
CBI-2 motor programs. Repeated EN programs enhance the efficacy of B20 in promoting egestive responses such that subsequent EN programs and CBI-2 programs are strongly egestive (Jing and Weiss, 2001; Proekt et al., 2004, 2007; Wu et al., 2010), consistent with the notion that a network state enhances the module that promotes a given behavior, to the detriment of other incompatible behaviors. However, network states can promote the generation of behaviors that could interfere with each other. Sleep deprivation promotes both sleeping and feeding (Rechtschaffen et al., 2002; McDonald and Keene, 2010), and noxious stimuli can promote both defensive behaviors and behaviors like feeding (Jing et al., 2008) or grooming (Rowell, 1961). These examples involve separate neural circuits, yet two features of the nervous system allow network states to promote the generation of incompatible behaviors by a single neural network. First, network states affect both behaviorspecific and independent modules, and second, the members of a module are heterogeneous.

Network states influence behavior-specific and behaviorindependent network modules

The multifunctional capacity of the nervous system often results from the activation of different network modules implementing distinct and overlapping aspects of a behavior. For instance, dif- 


\section{Stimulus}

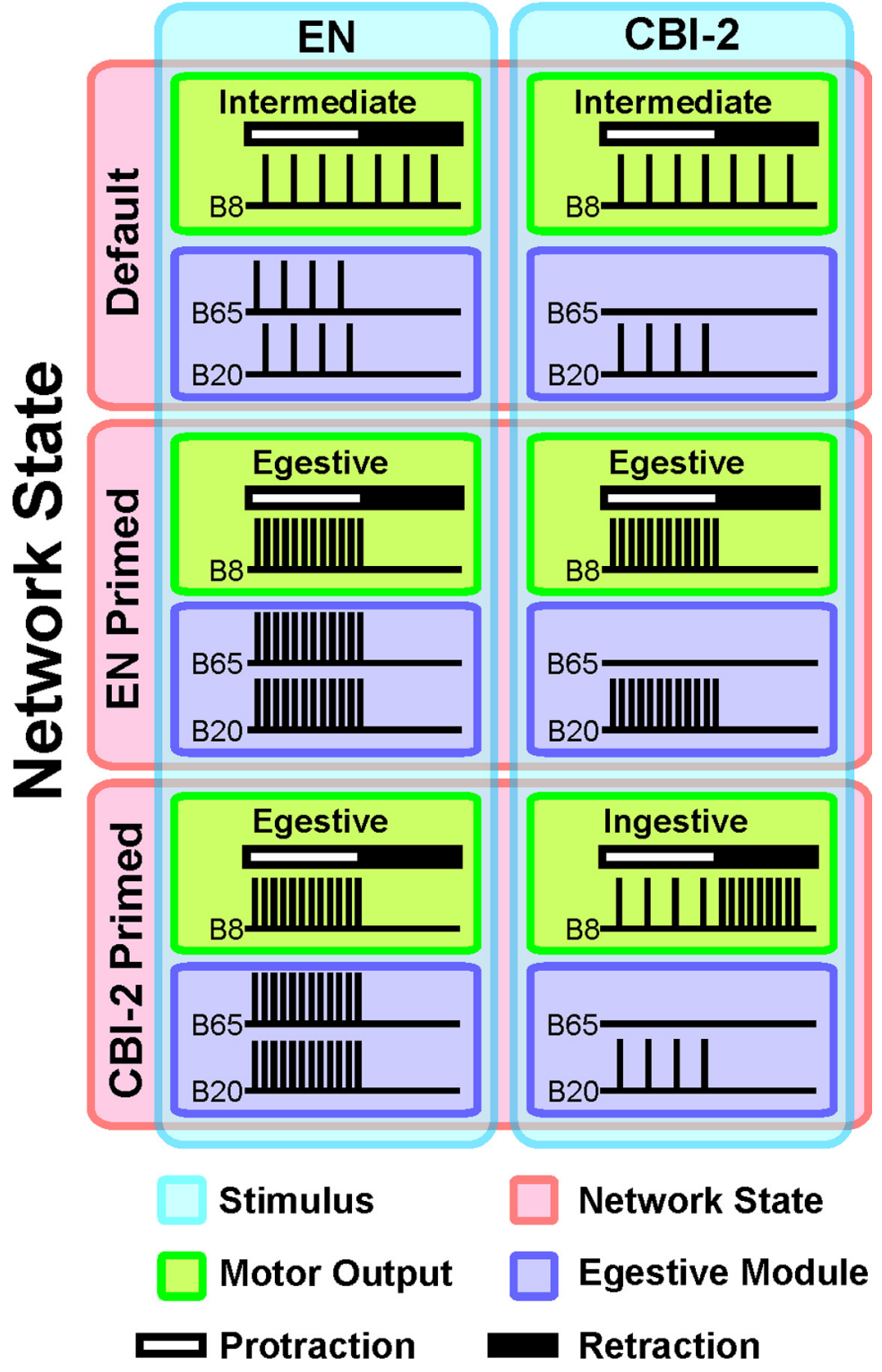

Figure 10. Network module heterogeneity endows the network with the flexibility needed to promote one behavior preferentially or antagonistic behaviors simultaneously. The nature of buccal motor outputs (Green) is defined by the phasing of the output neuron B8 whose activity in protraction (white bar) vs retraction (black bar) is indicative of egestive vs ingestive motor programs, respectively. Motor programs are triggered by different stimuli (Blue), specifically stimulation of the EN or interneuron $\mathrm{CBI}-2$, and are codetermined by the network state (Red). In the default state (i.e., before the establishment of either the CBI-2 or EN primed state), stimulation of either (BI-2 or EN triggers a response that is intermediate, i.e., neither ingestive nor egestive. Motor output is egestive when the egestive interneuronal modules (Purple) are active. After repeated EN programs, subsequent EN responses are strongly egestive as the influence of $\mathrm{B} 20$ and $\mathrm{B} 65$ (both members of the egestive module) are enhanced. Likewise, repeated $\mathrm{CBI}-2$ stimulation causes subsequent $\mathrm{CBI}-2$ motor programs to be strongly ingestive. Thus, establishing a historydependent network state by repeatedly eliciting motor programs via one stimulus enhances subsequent responses to that stimulus. In the EN primed state, CBI-2 stimulation elicits egestive rather than ingestive responses, due to an increase in the efficacy of the neuron $\mathrm{B} 20$, which is active both in $\mathrm{EN}$ - and in CBI-2-elicited motor programs. This is consistent with the idea that network states promote modules that enhance the articulation of one response and interfere with the articulation of antagonistic responses. Contrary to this assumption, EN motor programs triggered in a CBI-2 primed state are actually strongly egestive. In this study, we show that this is accomplished because $\mathrm{CBI}-2$ priming latently modulates the excitability of $\mathrm{B} 65$, thus enhancing the implementation of egestive EN programs. Yet, because $\mathrm{B} 65$ is not active in $\mathrm{CBI}-2$ motor programs this latent modulation does not interfere with the articulation of ingestive $\mathrm{CBI}-2$ motor programs. Thus, the influence of the network state on a member of a behavioral module is not realized until the appropriate stimulus is encountered. Note that $\mathrm{B} 20$ activity in EN programs in the $\mathrm{CBI}-2$ primed state is assumed to increase as B65 provides direct excitatory input to B20. ferent sequences of activation of the motor neurons implementing knee extension and hip flexion/extension in the turtle hindlimb result in diverse behaviors (Berkowitz, 2002b，2005，2010; Stein, 2010). Modules can implement components of a behavior or control the activation of other modules, thus making the consequences of network state modulation complex. In Aplysia, CBI-2 priming affects the excitability of neurons in the protraction/retraction module (Koh et al., 2003; Koh and Weiss, 2005, 2007), egestion module (this study), and opener/ closer module (Friedman and Weiss, 2010; Dacks et al., 2012), increasing both the strength and the relative phasing of motor output. Thus, because network states affect functionally diverse sets of modules (Jing et al., 2004), the consequences of network states manifest themselves across levels of organization and across behaviors.

Member neurons of network modules are heterogeneous

The consequences of network states for the output of network modules are further complicated by the heterogeneity of the individual neurons comprising a given module. Although the members of modules are assigned based on the functional consequences of their activation, they can differ in their intrinsic properties. The MNISN-1s and MN1-1b motoneurons in larval Drosophila project to overlapping sets of muscles (Choi et al., 2004) yet differ in their intrinsic biophysical properties (Choi et al., 2004; Worrell and Levine, 2008; Schaefer et al., 2010), resulting in differences in their contribution to motor output (Schaefer et al., 2010). Furthermore, members of a module can receive different inputs even if they all contribute toward the execution of the same functional output. In crabs, projection neurons coactivating gastric mill rhythms receive similar excitatory input in the commissural ganglion (Blitz et al., 2004), yet different inhibitory input in the stomatogastric ganglion (Beenhakker et al., 2007). In the buccal ganglion of Aplysia, heterogeneity within the egestion module has significant consequences for the effects of network state and input stimulus on network output. Figure 10 schematizes the activity of B20 and B65 in CBI-2 and EN motor programs generated while the network is in different states, highlighting the consequences of modular heterogeneity for motor output. B20 and B65 differ in that B20 is state-specific (i.e., only modulated by $\mathrm{EN}$ priming), while $\mathrm{B} 65$ is 
stimulus-specific (i.e., only active during EN programs). This heterogeneity allows $\mathrm{EN}$ priming to promote egestion during either EN (via B20 and B65) or CBI-2 motor programs (via B20), and preserves the generation of egestive EN responses after CBI-2 priming (via B65 and consequently B20). Thus, intramodular heterogeneity affords the network far more flexibility than if network modules were monolithic groups of neurons.

Interestingly, in Aplysia, up-modulation of the feeding network following activation of the locomotor network is conditionally expressed, as locomotion and feeding are implemented by separate networks. Each network is activated by different stimuli and the feeding network remains silent during activation of the locomotor network (Jing et al., 2008). Ingestive and egestive responses are mediated by a single network, but the modulation of these behaviors is segregated by the selective activation of B65 in EN programs. Therefore, $\mathrm{B} 65$ operates as if it were a member of a separate network. Thus, similar mechanisms support the enhancement of incompatible behaviors across and within neural networks.

\section{Neuropeptides mediate the influence of network states at a variety of organizational levels}

Neuropeptides are used across a wide phylogenetic spectrum to modulate neural networks within a specific behavioral context. For instance, neuropeptide $\mathrm{Y}$ homologues act within the context of feeding in mollusks (Jing et al., 2007), insects (Wu et al., 2003, 2005; Root et al., 2011), nematodes (de Bono and Bargmann, 1998; Rogers et al., 2003), and mammals (Batterham et al., 2002; Kalra and Kalra, 2004). A single neural network can also use many neuropeptides to modulate network output in a variety of ways. For instance, more than a dozen functionally characterized neuropeptides are present in the stomatogastric ganglion (Christie et al., 2010) and many neuropeptides alter the motor output of the feeding CPG of Aplysia in a variety of physiological contexts (Furukawa et al., 2001; Li et al., 2001; Morgan et al., 2002; Sweedler et al., 2002; Furukawa et al., 2003; Proekt et al., 2005; Jing et al., 2007, 2010; Vilim et al., 2010). In the buccal ganglion of Aplysia, FCAP and CP2 affect the implementation of protraction/retraction (Koh et al., 2003; Koh and Weiss, 2005, 2007) and radula opening (Friedman and Weiss, 2010), and bias the nature of motor programs via B65 (Figs. 8, 9), demonstrating that neuropeptides can contribute to the establishment of network states at many levels of network organization. Furthermore, SCP release during EN priming also enhances B65 activity (Wu et al., 2010), suggesting that distinct network states use different neuropeptides to target overlapping sets of neurons. The enhancement of egestive responses via diverse mechanisms further illustrates that the nervous system can use many different mechanisms to converge upon the same output (Prinz et al., 2004; Goaillard et al., 2009).

From an evolutionary perspective, it is not surprising that different network states can promote a single behavior. Some behaviors have greater impact on survival than others, as illustrated by the "life-dinner" principle in which there is greater selective pressure for prey to avoid being eaten than there is for a predator to obtain a meal (Dawkins and Krebs, 1979). In the context of this study, the benefit of rejecting an inedible or aversive food stimulus (e.g., egestion) outweighs the benefits of consuming a single meal (e.g., ingestion). Consistent with this, the efficacy of the egestive module is enhanced during the establishment of a network state in which ingestive behavior is promoted.
From this vantage, network states allow the nervous system to optimize responses to repeatedly encountered stimuli by altering the properties of neurons active across several types of responses (i.e., B20), yet also protects the ability to generate critical responses across different network states (i.e., B65). Furthermore, by affecting multiple levels of network organization, network states bias different aspects of response articulation. Network states therefore do not merely enhance the modules underlying the implementation of a given behavior, but also modules operating at different levels of network organization that are themselves comprised of individual elements active in different behaviors.

\section{References}

Batterham RL, Cowley MA, Small CJ, Herzog H, Cohen MA, Dakin CL, Wren AM, Brynes AE, Low MJ, Ghatei MA, Cone RD, Bloom SR (2002) Gut hormone PYY(3-36) physiologically inhibits food intake. Nature 418: 650-654. CrossRef Medline

Beenhakker MP, Kirby MS, Nusbaum MP (2007) Mechanosensory gating of proprioceptor input to modulatory projection neurons. J Neurosci 27:14308-14316. CrossRef Medline

Berkowitz A (2002a) Endogenous biotin staining in a subset of spinal neuronal cell bodies: a potential confounding factor for neuroanatomical studies. Brain Res 938:98-102. CrossRef Medline

Berkowitz A (2002b) Both shared and specialized spinal circuitry for scratching and swimming in turtles. J Comp Physiol A Neuroethol Sens Neural Behav Physiol 188:225-234. CrossRef Medline

Berkowitz A (2005) Physiology and morphology indicate that individual spinal interneurons contribute to diverse limb movements. J Neurophysiol 94:4455-4470. CrossRef Medline

Berkowitz A (2010) Multifunctional and specialized spinal interneurons for turtle limb movements. Ann N Y Acad Sci 1198:119-132. CrossRef Medline

Bizzi E, Mussa-Ivaldi FA, Giszter S (1991) Computations underlying the execution of movement: a biological perspective. Science 253:287-291. CrossRef Medline

Blitz DM, Beenhakker MP, Nusbaum MP (2004) Different sensory systems share projection neurons but elicit distinct motor patterns. J Neurosci 24:11381-11390. CrossRef Medline

Briggman KL, Kristan WB (2008) Multifunctional pattern-generating circuits. Annu Rev Neurosci 31:271-294. CrossRef Medline

Choi JC, Park D, Griffith LC (2004) Electrophysiological and morphological characterization of identified motor neurons in the Drosophila third instar larva central nervous system. J Neurophysiol 91:2353-2365. CrossRef Medline

Christie AE, Stemmler EA, Dickinson PS (2010) Crustacean neuropeptides. Cell Mol Life Sci 67:4135-4169. CrossRef Medline

Dacks AM, Siniscalchi MJ, Weiss KR (2012) Removal of default-state associated inhibition during repetition priming improves response articulation. J Neurosci 32:17740-17752. CrossRef Medline

d'Avella A, Saltiel P, Bizzi E (2003) Combinations of muscle synergies in the construction of a natural motor behavior. Nat Neurosci 6:300-308. CrossRef Medline

Dawkins R, Krebs JR (1979) Arms races between and within species. Proc R Soc Lond B Biol Sci 205:489-511. CrossRef Medline

de Bono M, Bargmann CI (1998) Natural variation in a neuropeptide Y receptor homolog modifies social behavior and food response in C. elegans. Cell 94:679-689. CrossRef Medline

Díaz-Ríos M, Miller MW (2005) Rapid dopaminergic signaling by interneurons that contain markers for catecholamines and GABA in the feeding circuitry of Aplysia. J Neurophysiol 93:2142-2156. Medline

Due MR, Jing J, Weiss KR (2004) Dopaminergic contributions to modulatory functions of a dual-transmitter interneuron in Aplysia. Neurosci Lett 358:53-57. CrossRef Medline

Friedman AK, Weiss KR (2010) Repetition priming of motoneuronal activity in a small motor network: intercellular and intracellular signaling. J Neurosci 30:8906-8919. CrossRef Medline

Furukawa Y, Nakamaru K, Wakayama H, Fujisawa Y, Minakata H, Ohta S, Morishita F, Matsushima O, Li L, Romanova E, Sweedler JV, Park JH, Romero A, Cropper EC, Dembrow NC, Jing J, Weiss KR, Vilim FS (2001) 
The enterins: a novel family of neuropeptides isolated from the enteric nervous system and CNS of Aplysia. J Neurosci 21:8247-8261. Medline

Furukawa Y, Nakamaru K, Sasaki K, Fujisawa Y, Minakata H, Ohta S, Morishita F, Matsushima O, Li L, Alexeeva V, Ellis TA, Dembrow NC, Jing J, Sweedler JV, Weiss KR, Vilim FS (2003) PRQFVamide, a novel pentapeptide identified from the CNS and gut of Aplysia. J Neurophysiol 89: 3114-3127. CrossRef Medline

Gardner D (1977) Interconnections of identified multiaction interneurons in buccal ganglia of Aplysia. J Neurophysiol 40:349-361. Medline

Gardner D, Kandel ER (1977) Physiological and kinetic properties of cholinergic receptors activated by multiaction interneurons in buccal ganglia of Aplysia. J Neurophysiol 40:333-348. Medline

Goaillard JM, Taylor AL, Schulz DJ, Marder E (2009) Functional consequences of animal-to-animal variation in circuit parameters. Nat Neurosci 12:1424-1430. CrossRef Medline

Grillner S (2006) Biological pattern generation: the cellular and computational logic of networks in motion. Neuron 52:751-766. CrossRef Medline

Hurwitz I, Neustadter D, Morton DW, Chiel HJ, Susswein AJ (1996) Activity patterns of the $\mathrm{B} 31 / \mathrm{B} 32$ pattern initiators innervating the $\mathrm{I} 2$ muscle of the buccal mass during normal feeding movements in Aplysia californica. J Neurophysiol 75:1309-1326. Medline

Hurwitz I, Perrins R, Xin Y, Weiss KR, Kupfermann I (1999) C-PR neuron of Aplysia has differential effects on "Feeding" cerebral interneurons, including myomodulin-positive CBI-12. J Neurophysiol 81:521-534. Medline

Jing J, Weiss KR (2001) Neural mechanisms of motor program switching in Aplysia. J Neurosci 21:7349-7362. Medline

Jing J, Weiss KR (2002) Interneuronal basis of the generation of related but distinct motor programs in Aplysia: implications for current neuronal models of vertebrate intralimb coordination. J Neurosci 22: 6228-6238. Medline

Jing J, Weiss KR (2005) Generation of variants of a motor act in a modular and hierarchical motor network. Curr Biol 15:1712-1721. CrossRef Medline

Jing J, Cropper EC, Hurwitz I, Weiss KR (2004) The construction of movement with behavior-specific and behavior-independent modules. J Neurosci 24:6315-6325. CrossRef Medline

Jing J, Vilim FS, Horn CC, Alexeeva V, Hatcher NG, Sasaki K, Yashina I, Zhurov Y, Kupfermann I, Sweedler JV, Weiss KR (2007) From hunger to satiety: reconfiguration of a feeding network by Aplysia neuropeptide Y. J Neurosci 27:3490-3502. CrossRef Medline

Jing J, Vilim FS, Cropper EC, Weiss KR (2008) Neural analog of arousal: persistent conditional activation of a feeding modulator by serotonergic initiators of locomotion. J Neurosci 28:12349-12361. CrossRef Medline

Jing J, Sweedler JV, Cropper EC, Alexeeva V, Park JH, Romanova EV, Xie F, Dembrow NC, Ludwar BC, Weiss KR, Vilim FS (2010) Feedforward compensation mediated by the central and peripheral actions of a single neuropeptide discovered using representational difference analysis. J Neurosci 30:16545-16558. CrossRef Medline

Kabotyanski EA, Baxter DA, Byrne JH (1998) Identification and characterization of catecholaminergic neuron B65, which initiates and modifies patterned activity in the buccal ganglia of Aplysia. J Neurophysiol 79:605621. Medline

Kalra SP, Kalra PS (2004) NPY - an endearing journey in search of a neurochemical on/off switch for appetite, sex and reproduction. Peptides 25:465-471. CrossRef Medline

Keene AC, Duboué ER, McDonald DM, Dus M, Suh GS, Waddell S, Blau J (2010) Clock and cycle limit starvation-induced sleep loss in Drosophila. Curr Biol 20:1209-1215. CrossRef Medline

Kiehn O, Kjaerulff O (1998) Distribution of central pattern generators for rhythmic motor outputs in the spinal cord of limbed vertebrates. Ann N Y Acad Sci 860:110-129. CrossRef Medline

Kiesel A, Steinhauser M, Wendt M, Falkenstein M, Jost K, Philipp AM, Koch I (2010) Control and interference in task switching — a review. Psychol Bull 136:849-874. CrossRef Medline

Koh HY, Weiss KR (2005) Peptidergic contribution to posttetanic potentiation at a central synapse of Aplysia. J Neurophysiol 94:1281-1286. CrossRef Medline

Koh HY, Weiss KR (2007) Activity-dependent peptidergic modulation of the plateau-generating neuron B64 in the feeding network of Aplysia. J Neurophysiol 97:1862-1867. Medline
Koh HY, Vilim FS, Jing J, Weiss KR (2003) Two neuropeptides colocalized in a command-like neuron use distinct mechanisms to enhance its fast synaptic connection. J Neurophysiol 90:2074-2079. CrossRef Medline

Kupfermann I (1974) Feeding behavior in Aplysia: a simple system for the study of motivation. Behav Biol 10:1-26. CrossRef Medline

Li L, Floyd PD, Rubakhin SS, Romanova EV, Jing J, Alexeeva VY, Dembrow NC, Weiss KR, Vilim FS, Sweedler JV (2001) Cerebrin prohormone processing, distribution and action in Aplysia californica. J Neurochem 77:1569-1580. CrossRef Medline

MacFadyen UM, Oswald I, Lewis SA (1973) Starvation and human slowwave sleep. J Appl Physiol 35:391-394. Medline

McDonald DM, Keene AC (2010) The sleep-feeding conflict: understanding behavioral integration through genetic analysis in Drosophila. Aging (Albany NY) 2:519-522.

Meiran N, Chorev Z, Sapir A (2000) Component processes in task switching. Cogn Psychol 41:211-253. CrossRef Medline

Morgan PT, Perrins R, Lloyd PE, Weiss KR (2000) Intrinsic and extrinsic modulation of a single central pattern generating circuit. J Neurophysiol 84:1186-1193. Medline

Morgan PT, Jing J, Vilim FS, Weiss KR (2002) Interneuronal and peptidergic control of motor pattern switching in Aplysia. J Neurophysiol 87:4961. Medline

Morton DW, Chiel HJ (1993a) In vivo buccal nerve activity that distinguishes ingestion from rejection can be used to predict behavioral transitions in Aplysia. J Comp Physiol A Neuroethol Sens Neural Behav Physiol 172:17-32. CrossRef

Morton DW, Chiel HJ (1993b) The timing of activity in motor neurons that produce radula movements distinguishes ingestion from rejection in $A p$ lysia. J Comp Physiol A Neuroethol Sens Neural Behav Physiol 173:519_ 536.

Nargeot R, Baxter DA, Byrne JH (1999a) In vitro analog of operant conditioning in Aplysia. II. Modifications of the functional dynamics of an identified neuron contribute to motor pattern selection. J Neurosci 19: 2261-2272. Medline

Nargeot R, Baxter DA, Byrne JH (1999b) In vitro analog of operant conditioning in Aplysia. I. Contingent reinforcement modifies the functional dynamics of an identified neuron. J Neurosci 19:2247-2260. Medline

Phares GA, Walent JH, Niece RL, Kumar SB, Ericsson LH, Kowalak JA, Lloyd PE (1996) Primary structure of a new neuropeptide, cerebral peptide 2, purified from cerebral ganglia of Aplysia. Biochemistry 35: 5921-5927. CrossRef Medline

Prinz AA, Bucher D, Marder E (2004) Similar network activity from disparate circuit parameters. Nat Neurosci 7:1345-1352. CrossRef Medline

Proekt A, Brezina V, Weiss KR (2004) Dynamical basis of intentions and expectations in a simple neuronal network. Proc Natl Acad Sci U S A 101:9447-9452. CrossRef Medline

Proekt A, Vilim FS, Alexeeva V, Brezina V, Friedman A, Jing J, Li L, Zhurov Y, Sweedler JV, Weiss KR (2005) Identification of a new neuropeptide precursor reveals a novel source of extrinsic modulation in the feeding system of Aplysia. J Neurosci 25:9637-9648. CrossRef Medline

Proekt A, Jing J, Weiss KR (2007) Multiple contributions of an inputrepresenting neuron to the dynamics of the Aplysia feeding network. J Neurophysiol 97:3046-3056. CrossRef Medline

Proekt A, Wong J, Zhurov Y, Kozlova N, Weiss KR, Brezina V (2008) Predicting adaptive behavior in the environment from central nervous system dynamics. PLoS One 3:e3678. CrossRef Medline

Rechtschaffen A, Bergmann BM, Everson CA, Kushida CA, Gilliland MA (2002) Sleep deprivation in the rat: $\mathrm{X}$. Integration and discussion of the findings. 1989. Sleep 25:68-87. Medline

Rogers C, Reale V, Kim K, Chatwin H, Li C, Evans P, de Bono M (2003) Inhibition of Caenorhabditis elegans social feeding by FMRFamiderelated peptide activation of NPR-1. Nat Neurosci 6:1178-1185. CrossRef Medline

Rogers RD, Monsell S (1995) Costs of a predictable switch between simple cognitive tasks. J Exp Psychol Gen 124:207-231. CrossRef

Root CM, Ko KI, Jafari A, Wang JW (2011) Presynaptic facilitation by neuropeptide signaling mediates odor-driven food search. Cell 145: 133-144. CrossRef Medline

Rosen SC, Teyke T, Miller MW, Weiss KR, Kupfermann I (1991) Identification and characterization of cerebral-to-buccal interneurons implicated in the control of motor programs associated with feeding in Aplysia. J Neurosci 11:3630-3655. Medline 
Rowell TE (1961) Displacement grooming in the Chaffinch. Anim Behav 9:38-63. CrossRef

Schaefer JE, Worrell JW, Levine RB (2010) Role of intrinsic properties in Drosophila motoneuron recruitment during fictive crawling. J Neurophysiol 104:1257-1266. CrossRef Medline

Stein PS (2010) Alternation of agonists and antagonists during turtle hindlimb motor rhythms. Ann N Y Acad Sci 1198:105-118. CrossRef Medline

Sweedler JV, Li L, Rubakhin SS, Alexeeva V, Dembrow NC, Dowling O, Jing J, Weiss KR, Vilim FS (2002) Identification and characterization of the feeding circuit-activating peptides, a novel neuropeptide family of Aplysia. J Neurosci 22:7797-7808. Medline

Teyke T, Rosen SC, Weiss KR, Kupfermann I (1993) Dopaminergic neuron B20 generates rhythmic neuronal activity in the feeding motor circuitry of Aplysia. Brain Res 630:226-237. CrossRef Medline

Vilim FS, Alexeeva V, Moroz LL, Li L, Moroz TP, Sweedler JV, Weiss KR (2001) Cloning, expression and processing of the CP2 neuropeptide precursor of Aplysia. Peptides 22:2027-2038. CrossRef Medline

Vilim FS, Sasaki K, Rybak J, Alexeeva V, Cropper EC, Jing J, Orekhova
IV, Brezina V, Price D, Romanova EV, Rubakhin SS, Hatcher N, Sweedler JV, Weiss KR (2010) Distinct mechanisms produce functionally complementary actions of neuropeptides that are structurally related but derived from different precursors. J Neurosci 30: 131-147. CrossRef Medline

Worrell JW, Levine RB (2008) Characterization of voltage-dependent $\mathrm{Ca} 2+$ currents in identified Drosophila motoneurons in situ. J Neurophysiol 100:868-878. CrossRef Medline

Wu JS, Vilim FS, Hatcher NG, Due MR, Sweedler JV, Weiss KR, Jing J (2010) Composite modulatory feedforward loop contributes to the establishment of a network state. J Neurophysiol 103:2174-2184. CrossRef Medline

Wu Q, Wen T, Lee G, Park JH, Cai HN, Shen P (2003) Developmental control of foraging and social behavior by the Drosophila neuropeptide Y-like system. Neuron 39:147-161. CrossRef Medline

Wu Q, Zhang Y, Xu J, Shen P (2005) Regulation of hunger-driven behaviors by neural ribosomal S6 kinase in Drosophila. Proc Natl Acad Sci U S A 102:13289-13294. CrossRef Medline 